University of New Orleans

ScholarWorks@UNO

Department of Economics and Finance Working

Papers, 1991-2006

Department of Economics and Finance

2006

\title{
Volatility Clustering, Leverage Effects, and Jump Dynamics in the US and Emerging Asian Equity Markets;
}

\author{
Elton Daal \\ University of New Orleans \\ Atsuyuki Naka \\ University of New Orleans \\ Jung-Suk Yu \\ University of New Orleans
}

Follow this and additional works at: https://scholarworks.uno.edu/econ_wp

\section{Recommended Citation}

Daal, Elton; Naka, Atsuyuki; and Yu, Jung-Suk, "Volatility Clustering, Leverage Effects, and Jump Dynamics in the US and Emerging Asian Equity Markets;" (2006). Department of Economics and Finance Working Papers, 1991-2006. Paper 36.

https://scholarworks.uno.edu/econ_wp/36

This Working Paper is brought to you for free and open access by the Department of Economics and Finance at ScholarWorks@UNO. It has been accepted for inclusion in Department of Economics and Finance Working Papers, 1991-2006 by an authorized administrator of ScholarWorks@UNO. For more information, please contact scholarworks@uno.edu. 


\title{
Volatility Clustering, Leverage Effects, and Jump Dynamics in the US and Emerging Asian Equity Markets
}

\author{
Elton Daal, Atsuyuki Naka, and Jung-Suk Yu* \\ Department of Economics and Finance \\ University of New Orleans
}

January 20, 2006

\begin{abstract}
This paper proposes asymmetric GARCH-Jump models that synthesize autoregressive jump intensities and volatility feedback in the jump component. Our results indicate that these models provide a better fit for the dynamics of the equity returns in the US and emerging Asian markets, irrespective whether the volatility feedback is generated through a common GARCH multiplier or a separate measure of volatility in the jump intensity function. We also find that they can capture several distinguishing features of the return dynamics in emerging markets, such as, more volatility persistence, less leverage effects, fatter tails, and greater contribution and variability of the jump component.
\end{abstract}

JEL Classification: C22, F31, G15

KEY WORDS: Volatility feedback, time-varying jump intensity, volatility clustering, leverage effect, leptokurtosis

\footnotetext{
*Corresponding author: Atsuyuki Naka, Department of Economics and Finance, University of New Orlelans, 2000 Lakeshore Drive, New Orleans, LA 70148. E-mail: anaka@uno.edu, tel: (504) 280-6487, fax: (504) 280-6397. We are grateful to two anonymous referees for providing us with many valuable comments. We also thank Oscar Varela, Gerald Whitney, Dilip Madan, and seminar participants at the University of New Orleans, the Erasmus University, and the 2005 Financial Management Association European Conference at Siena, Italy, for their helpful comments and discussions.
} 


\section{Abstract}

This paper proposes asymmetric GARCH-Jump models that synthesize autoregressive jump intensities and volatility feedback in the jump component. Our results indicate that these models provide a better fit for the dynamics of the equity returns in the US and emerging Asian markets, irrespective whether the volatility feedback is generated through a common GARCH multiplier or a separate measure of volatility in the jump intensity function. We also find that they can capture several distinguishing features of the return dynamics in emerging markets, such as, more volatility persistence, less leverage effects, fatter tails, and greater contribution and variability of the jump component. 


\section{Introduction}

Mixed GARCH-Jump modeling has emerged as a powerful tool to describe the dynamics of asset returns in discrete-time. Recent work in this area by, for example, Duan, Ritchken and Sun (2005a, 2005b) and Maheu and McCurdy (2004) allows for time-variation in the jump component of the mixed GARCH-Jump model. In particular, Duan et al. develop a constant intensity NGARCH-Jump model that allows for time-variation through a common GARCH multiplier in the "diffusion" and jump component. ${ }^{1}$ In the limit, their discrete-time model can converge to continuous-time jump-diffusion processes with jumps in the stochastic volatility. They find that the NGARCH-Jump model provides a better fit for the time-series of S\&P 500 index returns relative to the normal NGARCH specification. Maheu and McCurdy develop a mixed GARCH-Jump model that admits separate time-variation and clustering in the jump intensity, but does not accommodate for volatility feedback in the jump component. When applied to individual stocks and indices in the US, their model outperforms the GARCHJump model with constant intensity and i.i.d. jump component. These findings give rise to the question which jump structure best fits the asset return dynamics under an asymmetric GARCH specification. Is it volatility feedback in the jump component, autoregressive jump intensity, or a combination of both? Should volatility feedback in the jump component be generated through a common GARCH multiplier or a separate measure of volatility in the jump intensity function?

To answer these questions, we propose asymmetric GARCH-Jump models that synthesize autoregressive jump intensities and volatility feedback in the jump component. We offer two extensions of the existing GARCH-Jump models. First, we extend the constant intensity asymmetric GARCH-Jump model in Duan et al. (2005a, 2005b) by accommodating for time-varying, autoregressive jump intensity. This extension allows for two sources of time-

\footnotetext{
${ }^{1}$ Strictly speaking, the term "diffusion" is only applicable in the continuous-time setting. In the remainder of the paper, we use it loosely to refer to the component of the mixed GARCH-Jump model that captures the normal innovations.
} 
variation in the jump component, namely, the common GARCH multiplier and the separate autoregressive arrival rate of jumps. Each factor affects the variation in jumps in a different way. The common GARCH multiplier induces time-variations in the jump component that are synchronous with the diffusion component, making these two components inseparable. In contrast, the autoregressive intensity allows the probability of jumps to change over time and can generate variations in the jump component that are fully separable from the diffusion component.

Second, we extend Maheu and McCurdy (2004) specification by allowing the jump intensity to be a non-affine function of the return volatility or its proxy. Studies in the continuoustime literature by Bates (2000), Duffie, Pan, and Singleton (2000), and Pan (2002) point to the importance of incorporating volatility in the random jump intensity. They show that a high volatility before and during a market crash can increase the probability of jumps. Chernov, Gallant, Ghysels, and Tauchen (1999) observe, however, that the return volatility tends to remain high after a market crash, while the arrival of jumps drops considerably after a crash. To accommodate both relationships, we use the absolute value of the equity returns as a measure of return volatility since it permits the jump intensity to be a non-affine function of the volatility. In this extended model, the GARCH multiplier is a scale factor for only the diffusion component and the contribution of each component is fully separable.

As in Duan et al. (2005a, 2005b) and Maheu and McCurdy (2004), both extended GARCH-Jump models incorporate jumps in the returns and volatilities. The inclusion of jumps in the volatility can potentially account for the large, but persistent movements in the emerging market volatility. The models allow conditional volatility to respond asymmetrically to both normal innovations and jump shocks. They can therefore accommodate both positive and negative correlations between the asset returns and volatilities. In addition, our extended models generate stochastic volatility from two different sources, the GARCH effects and the arrival rate of jumps. The main difference between the two extended models is the 
way they allow for volatility feedback in the jump component. We compare these models to examine whether volatility feedback through a common GARCH multiplier or a separate measure of return volatility in the jump intensity is more appropriate to describe the return dynamics.

In addition, this paper investigates whether the proposed GARCH-Jump models can capture the distinguishing features of return dynamics in the emerging equity markets. As documented in the literature, equity returns from emerging markets exhibit different characteristics compared to those from developed markets. For example, Harvey (1995) and Bekaert and Harvey (2002) argue that emerging market returns have higher volatility, fatter tails, and greater predictability. In contrast to the mature markets, Bekaert and Harvey (1997) show that volatilities in emerging markets are primarily determined by local information variables. Aggarwal, Inclan and Leal (1999) find that the volatilities in emerging markets exhibit large and sudden shifts. They find that these jump-like changes in the emerging markets' volatility are primarily associated with important local events. Aggarwal et al. also find that most emerging markets' returns show positive skewness, which is in contrast to the negative skewness in developed markets.

We therefore apply our models to daily index returns in both the US and Asian equity markets. We select a diversified group of emerging Asian markets, ranging from countries that were severely affected by the 1997 Asian financial crisis to those that were relatively unaffected. We consider a sample period from July 5, 1995 through August 7, 2002, which allows us to examine the dynamics of the Asian equity returns before, during, and after the crisis. To evaluate the contribution of each models' component, we estimate and test several special cases of the models. The main results can be summarized as follows.

Overall, while no one model fits best in all markets, we find that the jump structures with autoregressive jump intensity and volatility feedback in the jump component provide a better fit for the dynamics of the equity returns in the US and most of the emerging 
Asian markets. The extended GARCH-Jump models outperform the specifications that only accommodate a common GARCH multiplier or autoregressive jump intensity. The rejection of the common GARCH multiplier as the only source of time-variation in both the diffusion and jump component is more evident in the presence of market crashes, pointing thereby toward the need for a separate source of time-variation in the jump component. When comparing the extended models with each other, we find that, on a aggregate level, volatility feedback through a separate measure of volatility in the jump intensity function performs as well as the common GARCH multiplier. However, the results for the individual parameter estimates suggest that the autoregressive arrival rate is more compatible with a volatility feedback through a separate state variable in the jump intensity function than with a common GARCH multiplier.

Further, we find that the extended GARCH-Jump models can capture several stylized facts in the volatilities and jump dynamics of the returns in the US and the emerging equity markets. The results indicate that the return volatility in these markets is stochastic, persistent, and asymmetric; the volatility persistence in the emerging markets is higher than in the US; the leverage effect is higher in the US; the returns as well as the volatilities exhibit jump discontinuities; volatilities respond asymmetrically to jump shocks in both the US and emerging markets; and jumps play a more predominant role and induce a quite different tail behavior in the emerging markets;

The remainder of the paper is structured as follows. In Section 2, we present the extended GARCH-Jump models that allow for volatility feedback and time-varying autoregressive jump intensities. Section 3 presents the data and estimation method. The results are discussed in Section 4 and Section 5 provides the conclusion of the paper. 


\section{Model Specifications}

\subsection{The extended models}

Under the general specification, the dynamics of the index returns, $r_{t}$, is given by

$$
r_{t}=\ln \left(\frac{S_{t}}{S_{t-1}}\right)=\mu+\varepsilon_{t}
$$

where

$$
\begin{aligned}
\varepsilon_{t} & =\varepsilon_{1, t}+\varepsilon_{2, t} \\
\varepsilon_{1, t} & =\sqrt{h_{t}} z_{t} \\
\varepsilon_{2, t} & =\sqrt{h_{t}^{k}}\left(\sum_{i=1}^{N_{t}} J_{i, t}-\phi \lambda_{t}\right) \text { where } k \in\{0,1\} \\
z_{t} \mid I_{t-1} & \sim \operatorname{NID}(0,1) \\
J_{i, t} & \sim \operatorname{NID}\left(\phi, \delta^{2}\right) \text { for } i=1,2, \ldots . .,
\end{aligned}
$$

$S_{t}$ is the daily closing price of the stock index (including accumulated interest or dividends), $N_{t}$ is a Poisson random variable with conditional jump intensity $\lambda_{t}, J_{i, t}$ is the random jump size, $\phi$ is the mean jump size, $\delta^{2}$ is the jump variability, $k$ is a dummy variable that indicates no GARCH effects on the jump component when $k=0$ and a common GARCH multiplier when $k=1$, and $I_{t-1}$ is the information set available at the beginning of time $t$. The Poissondistributed variable, $N_{t}$, and the random jump size, $J_{i, t}$, are contemporaneously uncorrelated with each other and with $z_{t}$. The aggregate stochastic innovation, $\varepsilon_{t}$, consists of a normal "diffusion" component, $\varepsilon_{1, t}$, and a jump component, $\varepsilon_{2, t}$.

We allow the conditional variance, $h_{t}$, of the diffusion component to follow an asymmetric GARCH process. As shown in Duan (1997), there are many suitable candidate models for the asymmetric GARCH specification. Without loss of generality, for robustness and 
comparison purposes, we choose two asymmetric GARCH models that have been used in the finance literature on asset return dynamics and option pricing, namely, the nonlinear GARCH (NGARCH) model employed in Duan, Ritchken, and Sun (2005a, 2005b) and Duan and Zhang (2001), and the power-GARCH (PGARCH) model used in Ding, Granger, and Engle (1993) and Heston and Nandi (2000). ${ }^{2}$ The NGARCH(1,1) and PGARCH(1,1) specifications are respectively given by

$$
\begin{gathered}
h_{t}=\alpha_{0}+\alpha_{1} h_{t-1}\left(\varepsilon_{t-1}-\theta\right)^{2}+\beta h_{t-1} \\
h_{t}=\alpha_{0}+\alpha_{1}\left(\left|\varepsilon_{t-1}\right|-\theta \varepsilon_{t-1}\right)^{2}+\beta h_{t-1} .
\end{gathered}
$$

To guarantee positive $h_{t}$, the parameter restrictions are $\alpha_{0}>0, \alpha_{1} \geq 0$, and $\beta \geq 0$ for both asymmetric GARCH specifications. ${ }^{3}$ The parameter $\beta$ captures volatility clustering and $\theta$ allows for asymmetric shock effects in the conditional variance. For $\theta>0$, an aggregate negative shock $\left(\varepsilon_{t-1}<0\right)$ increases the variance more than an aggregate positive shock $\left(\varepsilon_{t-1}>0\right)$. This asymmetry implies a negative correlation between the index returns and the conditional volatility, and is loosely referred to as the leverage effect. ${ }^{4}$ As in Maheu and McCurdy (2004) and Duan et al. (2004, 2005), the conditional volatility can respond asymmetrically to both normal innovations $\left(\varepsilon_{1, t-1}\right)$ and jump shocks $\left(\varepsilon_{2, t-1}\right)$.

The specification in Equation (1), combined with either (2a) or (2b), incorporates jumps in both the returns and volatilities. We see that the current jump events are incorporated immediately in the current prices, while they have an impact on the future expected volatility. Several recent studies find that accommodating for jumps in the return and volatility process

\footnotetext{
2 For a detailed discussion on the properties of the PGARCH specification, we refer to Ding, Granger, and Engle (1993).

3 Stationarity requires that $\beta+\alpha_{1}\left(1+\theta^{2}\right) \leq 1$ for the NGARCH and PGARCH specifications.

4 As noted in Bekaert and $\mathrm{Wu}$ (2000) and $\mathrm{Wu}$ (2001), leverage effect entails that bad news reduces the value of the stock, which in turn increases financial leverage, making the stock riskier and, hence, its volatility higher. Alternatively, a negative correlation can also be induced by the systematic component of the volatility. That is, when volatility is priced, its increase causes an increase in the expected return, resulting in a drop in the current stock price.
} 
considerably improves the model's fit for the return data of matured equity markets. ${ }^{5}$ We expect similar, or even greater improvements for the emerging equity markets. As documented in Aggarwal et al. (1999), the emerging markets are characterized by high volatilities and exhibit large, sudden changes in the variance. The inclusion of jumps in the volatility process can account for these large, but persistent movements in the emerging markets' volatility.

For the arrival rate of jumps, $\lambda_{t}$, we build on the autoregressive conditional jump intensity model presented in Maheu and McCurdy. In their model, the conditional jump intensity, $\lambda_{t}$, depends on the last period's conditional intensity, $\lambda_{t-1}$, and an intensity residual, $\xi_{t-1}$. In our general specification, the conditional jump intensity can also be a function of a state variable,

$$
\lambda_{t}=\lambda_{0}+\rho \lambda_{t-1}+\gamma_{1} \xi_{t-1}+\gamma_{2}\left|x_{t-1}\right|^{(1-k)},
$$

where $\xi_{t-1}$ is the intensity residual,

$$
\xi_{t-1}=E\left[N_{t-1} \mid I_{t-1}\right]-\lambda_{t-1},
$$

with $E\left[N_{t-1} \mid I_{t-1}\right]$ being the ex post probability of jumps, $\lambda_{t-1}$ the ex ante probability of jumps, and $x_{t-1}$ the state variable. In Appendix I, we present the explicit expression for the ex post probability. The jump structure with autoregressive jump intensity allows for clustering in the jump likelihood and induces variations in the return volatility.

The dummy variable $k$ in equations (1) and (3) determines the type of extended GARCHJump model under consideration. For $k=1$, the common GARCH multiplier in Duan et al. is extended with an autoregressive jump intensity. In accord with Duan et al., the scale factor, $h_{t}$ is a GARCH multiplier that simultaneously induces time-variation in both the diffusion and jump component. ${ }^{6}$ The extended model under $k=1$, which we denote hence-

\footnotetext{
${ }^{5}$ See, for example, Eraker (2004), Eraker et al. (2003), Duan et al. (2005), and Maheu and McCurdy (2004).

${ }^{6}$ We are grateful to an anonymous referee for pointing this out.
} 
forth as the JDMAI model, offers two distinguishing features. First, with regard to the jump structure, it allows for two sources of time-variation in the jump component, namely, the GARCH multiplier and the autoregressive jump intensity. Each factor affects the variation in jumps in a different way. The GARCH multiplier allows volatility to feedback directly in the jump component. It induces therefore variations in the jump component that cannot be disentangled from the diffusion component. In contrast, the autoregressive intensity allows the probability of jumps to change over time and can generate variations in the jump component that are independent of the diffusion component. Second, while most GARCH-Jump models permit either common or separate sources of variation in the return volatility, the JDMAI model incorporates both common $\left(h_{t}\right)$ and separate $\left(\lambda_{t}\right)$ sources.

For $k=0$, the Maheu and McCurdy specification is extended with a state variable in the jump intensity function. In this extended model, which is denoted hereafter as the JDSI model, the GARCH multiplier, $h_{t}$, is a scale factor for only the diffusion component. Hence, the contribution of each component is fully separable. For the state variable, $x_{t-1}$, we choose the absolute value of the equity returns because it can be considered as a measure of return volatility. It allows for the jump intensity to be a non-affine function of the volatility. Such a specification can capture the positive correlation between volatility and jump arrivals during a distress, but it is also suitable when high return volatility after a market crash is accompanied by decreasing arrival rate of jumps.

Alternatively, we also allow the state variable, $x_{t-1}$, to be the lagged changes in the exchange rate vis-à-vis the US dollar for the emerging Asian markets. Our motivation for incorporating lagged currency returns as an information variable in the jump structure of these markets is twofold: First, exchange rate realignments capture macro-economic conditions in the emerging markets and play therefore an important role during periods of major crisis in these markets. Recent examples include the Mexican Peso (1994), the Thai Bhat (1997), the Malaysian Ringgit (1997), the Russian GKO's (1998), and the Brazilian Real (1999). 
In the case of the Asian crisis, Kaminsky and Schmukler (1999) note that the devaluations resulted in sharp decreases in both the dollar and local stock returns. Maroney, Naka, and Wansi (2004) attribute this reduction in the average returns to the fact that the Asian firms were heavily leveraged in the foreign currency. Second, the absolute value of the currency returns is, at least partially, a measure of the volatility of the dollar return of the stock index. Maroney et al. show that in the post-crash period, half of the volatility of dollar returns in most Asian markets is due to exchange rate movements.

Following Das and Sundaram (1999), we find that the JDSI model-implied conditional variance, skewness, and kurtosis of the returns are given by

$$
\begin{gathered}
\operatorname{Var}\left(r_{t} \mid I_{t-1}\right)=h_{t}+\left(\phi^{2}+\delta^{2}\right) \lambda_{t} \\
\operatorname{Sk}\left(r_{t} \mid I_{t-1}\right)=\frac{\lambda_{t}\left(\phi^{3}+3 \phi \delta^{2}\right)}{\left(h_{t}+\lambda_{t} \delta^{2}+\lambda_{t} \phi^{2}\right)^{1.5}} \\
\mathrm{Ku}\left(r_{t} \mid I_{t-1}\right)=3+\frac{\lambda_{t}\left(\phi^{4}+6 \phi^{2} \delta^{2}+3 \delta^{4}\right)}{\left(h_{t}+\lambda_{t} \delta^{2}+\lambda_{t} \phi^{2}\right)^{2}} .
\end{gathered}
$$

In contrast to the JDMAI model, the total variation of the returns in Equation (5) can be fully decomposed into smooth, diffusion-driven variation, $h_{t}$, and jump-induced variation. For both the JDMAI and JDSI models, the conditional variance, $h_{t}$, affects the conditional skewness and excess kurtosis only when $\lambda_{t} \neq 0$. Hence, only jumps can conditionally induce non-normalities in the distribution of the index returns.

\subsection{The nested models}

In addition to the extended models, we use several special cases to gain more insights in the contribution of each model's features. To start with, for the JDMAI models, we turn off

the jumps, $\lambda_{t}=0$, to gauge the importance of asymmetry in the volatility structure and to examine the robustness of the asymmetric specifications across the equity markets. In this 
respect, we compare the asymmetric NGARCH and PGARCH models with each other and with the benchmark symmetric GARCH specification $(\theta=0)$.

Next, to isolate the impact of the GARCH multiplier as a source of time-variation in the jumps and volatility, we set $\lambda_{t}=\lambda$ in the JDMAI model. We label this special case as the JDM model. To examine the relative importance of the autoregressive jump intensity as an alternative source of time-variation, we impose $\gamma_{2}=0$ in the JDSI model. This special case of the JDSI model is referred to as the JDAI model. The model comparisons are effectuated for all three GARCH specifications. For notational convenience, we add the labels G, NG, or PG to refer respectively to the GARCH, NGARCH, or PGARCH component of each model. For example, the JDM model with an NGARCH multiplier is referred to as the JDM-NG model. In total, we have sixteen competing models. They are three GARCH specifications with no jumps, three GARCH specification with four jump structures (JDMAI, JDM, JDAI, and JDSI), and one GARCH-Jump model with the absolute value of lagged currency returns as the state variable.

\section{The Data and Estimation Method}

The data used in this study consist of daily closing prices for stock indexes from the US and eight emerging Asian markets (EAM). For the US, we use the time series data on the S\&P 500 obtained from the Center for Research in Security Prices (CRSP) data base. The eight EAM are China, India, Indonesia, Korea, Malaysia, Philippines, Taiwan, and Thailand. The EAM affected by the 1997 Asian financial crisis are Indonesia, Korea, Thailand, Malaysia and Philippines (henceforth, EAM-5), where Indonesia, Korea, and Thailand were hit the hardest. China, India, and Taiwan were relatively unaffected. The data for the EAM are obtained from the Standard and Poor's Emerging Markets Data Base (EMDB). All stock indexes are expressed in the US dollar terms. The sample covers the period from July 5, 
1995 through August 7, 2002. We filter out all zero returns, since those are returns that the EMDB conventionally report for the trading holidays. For most EAM, the zero returns constitute less than two percent of the full sample.

We divide the data into three sub-samples. The first sub-sample covers the pre-crisis period, starting from July 1995 to right before the official crisis date of each country. As indicated in Table 1, the crisis dates vary across countries. ${ }^{7}$ The second sub-sample refers to the crisis years, spanning the crisis-date in July through December 1999. The remainder of the sample, that is, January 2000 through August 2002, is considered the post-crisis period. Although the selection of the sub-samples is ad hoc in nature, each period gives roughly equal number of observations.

\section{[Insert Table 1 here]}

Panel A of Table 1 presents the summary statistics for the daily index returns for the whole sample period. Except for China, the average daily returns on the stock indexes are negative for all EAM during the full sample period. The index returns in China display a higher average than the S\&P 500, whereas the Thailand index records the lowest average in our sample. We notice that the index returns in most EAM exhibit large extremes. The maximum daily return observed in the EAM (Korea) and the US is respectively 26.79 and 5.57 percent, and the minimum is respectively -40.85 (Indonesia) and -7.11 percent. These extreme returns are detected primarily during the crisis period in Panel $\mathrm{C}$ and are concentrated in the EAM-5.

The time series plots of the index level and returns in figures 1 and 2 provide further illustration of the extreme movements in the EAM. In Table 1, Panel A, the standard deviation of the daily returns in all EAM is higher than in the US. It ranges from 1.65 percent for

\footnotetext{
${ }^{7}$ Maroney, Naka and Wansi (2004) estimate the dates of the structural changes during the crisis periods and provide the confidence intervals for six Asian countries. According to their estimates, the structural changes occur much later than the official dates.
} 
India to 3.68 percent for Indonesia. Except for China, these relatively high volatilities are accompanied by negative mean returns. This can be primarily attributed to the Asian crisis in 1997. As pointed out in Maroney et al. (2004), it is the high leverage linked to exchange rate that resulted into higher risk and lower mean returns when the Asian crisis began. The sub-sample statistics indicate large shifts in the volatility. Specifically, for most EAM, the volatilities during the crisis period are substantially higher than the volatilities before and after the crisis. For example, the pre-crisis volatility for Indonesia increases from 1.20 to 5.85 percent during the crisis, and then drops to 2.24 percent in the post-crisis period as shown in Panel B, C, and D.

\section{[Insert Figure 1 and 2 here]}

The non-normality of the returns, as measured by the skewness and kurtosis, is substantially larger for the EAM-5 countries relative to the US. For example, in Panel A, the sample kurtosis of the index returns in the EAM-5 countries ranges from 8.18 for Thailand to 24.25 for Malaysia. In Panel E, we observe that the exchange rates of all the EAM, excluding China, have depreciated vis-à-vis the US dollar. On average, Indonesia has the largest depreciation and standard deviation. Maroney et al. observe that the depreciation of these currencies have contributed to the negative dollar returns and increased volatilities in the EAM-5.

As for the estimation method, we use the maximum likelihood estimation for all model specifications. For robustness, we estimate the models for the whole sample and sub-sample periods. To save space, we only report the results for the whole sample period. For each model, the estimation involves maximizing the conditional log-likelihood function with respect to the parameter vector of that model. The conditional probability density function for the extended model is presented in the Appendix. As in Jorion (1988) and Maheu and McCurdy (2004), we find that truncation of the infinite sum in the likelihood at 10 captures all the tail probabilities and gleans sufficient precision in the estimation procedure. 
We use likelihood ratio (LR) tests and Akaike's information criterion (AIC) to examine the performance of the models relative to each other. ${ }^{8}$

\section{Results}

\subsection{Volatility clustering and leverage effects}

Table 2, Panel A and B, presents the specification tests for the GARCH, NGARCH, and PGARCH models. For all EAM and the US, the LR tests show that the asymmetric NGARCH and PGARCH significantly outperform the symmetric GARCH at a 5 percent significance level. These results indicate that volatility asymmetry is an important feature of the equity returns in both matured and emerging markets. We note, however, that the improvement in the fit for both the NGARCH and PGARCH is substantially larger for the US index returns. Under the NGARCH specification, the value of the log likelihood increases by 41.86 (from 5537.87 to 5579.73 ) for the US, while the largest increase is 15.04 for the EAM (Philippines). We infer therefore that volatility asymmetry plays a more important role in the US. When comparing the asymmetric models with each other, the log likelihoods and AIC suggest that the NGARCH and PGARCH model are almost indistinguishable.

\section{[Insert Table 2 here]}

According to Panel $\mathrm{C}$ of Table 2, the parameter estimates for the NGARCH models provide evidence that the return volatility in the matured and emerging markets is stochastic, persistent, and asymmetric. ${ }^{9}$ For example, the estimates for the parameter $\alpha_{1}$ of the NGARCH models are significant and show that the volatility is changing stochastically over

\footnotetext{
${ }^{8}$ We also employ the Schwarz criterion (BIC), but do not report these results since they are similar to AIC.

9 Since the performance of the two asymmetric GARCH models are indistinguishable, we present the parameter estimates only for the NGARCH models in the remainder of the paper. The parameter estimates for the PGARCH models are available upon request.
} 
time. The fact that all estimates for $\beta$ are positive and statistically significant provides evidence in favor of volatility clustering in these markets. The aggregate autoregressive coefficient in the volatility process is very close to one for the EAM-5 group, resulting in a persistence effect that is stronger than in the US. ${ }^{10}$ The positive values for the asymmetry parameter $\theta$ point toward leverage effects in the US and EAM. With an estimated value of 0.011 for $\theta$, the volatility of the US index returns is more asymmetric than that of the EAM. A possible explanation is that volatility risk is more systematic in the US as compared to the EAM. As noted in Harvey (1995) and Bekaert and Harvey (1997), the volatility in the emerging markets is primarily driven by local factors. These country-specific factors are either not priced or have a low correlation with the world market. In this respect, we notice that those EAM which are less integrated with the world market, e.g., China and Thailand, have the lowest estimate for the asymmetry parameter.

The sub-sample results suggest that the Asian crisis brought about significant changes in the volatility structure of several EAM.(not reported) $)^{11}$ The volatility clustering in most EAM-5 (except Korea) dropped substantially after the crisis period. For all markets, except Thailand, the post-crisis leverage effect is higher than before the crisis. For China and India, we observe a change from no leverage effect before the crisis to relatively high leverage effects after the crisis. Figure 3 graphs the time-series of conditional volatilities generated by the NGARCH model. It shows that the volatility exhibits more fluctuations in the crisis and postcrisis period as compared to the pre-crisis period. In addition, we also observe the presence of extreme large, abrupt movements in the volatility process in Figure 3. These jump-like characteristics of the volatility process in the emerging markets are also documented by Aggarwal et al. (1999).

\section{[Insert Figure 3 here]}

\footnotetext{
10 We use $\beta+\alpha_{1}$ as a proxy for the aggregate autoregressive coefficient.

11 The sub-sample results are not reported in Table 2, but are available upon request from the authors.
} 


\subsection{Which jump specification best fits the equity returns?}

Although conditional volatility in the form of asymmetric GARCH effects significantly improve the model performance, it needs a jump component to adequately describe the return dynamics. Table 3 reports the log likelihoods and the values of AIC for all GARCH-Jump models applied to the US and EAM index returns. We ascertain the role of jumps in the return dynamics by performing pairwise comparisons of the mixed GARCH-Jump models with their GARCH counterparts with no jumps. Across all equity markets and irrespective of the jump structure, the LR tests show that the mixed GARCH-Jump models strongly reject the GARCH specifications at 5 percent significance level. These results indicate that the equity returns in the US and EAM exhibit large, infrequent moves that cannot be captured by a diffusion process, even when volatility is stochastic. This implies that the return distributions of the indexes in these markets deviate significantly from the normal distribution.

\section{[Insert Table 3 here]}

To examine the different sources of time-variation in the jump component, we compare three jump structures for each GARCH specification. We formally perform LR tests to compare the JDMAI with the nested JDM models. According to Table 3, these tests show that the JDM models are rejected in favor of the JDMAI models under all three volatility specifications and for all equity returns, except India. This result suggests that the autoregressive jump intensity significantly improves the performance of the JDM models in these equity markets. It also implies that a common GARCH multiplier alone cannot capture all the dynamics of the jump component of the index return. This drawback of the JDM models seems to be more evident in the presence of market crashes. In particular, across all three volatility specifications, we observe that the superior performance of the JDMAI relative to the JDM is on average more pronounced for the EAM-5. 
We next compare the JDMAI with the JDAI models. Since these models are not nested, we use the AIC values for this comparison. For most cases and across volatility specifications, the AIC tests glean a superior performance for the JDMAI models. For the US and most EAM, it seems that allowing for an autoregressive jump intensity without additional sources of time-variation in the jump component is not sufficient to capture the dynamics of the index returns. We note, however, that the frequency and size of the underperformances of the JDAI models are less severe than those of the JDM models. When JDM and JDAI models are compared based on the values of AIC, we find that across GARCH specifications the JDAI outperforms the JDM in most cases (18 times out of 27 comparisons). Hence, although both sources of time-variation improve the fit significantly, the separate source in the form of autoregressive jump intensity appears to capture jump dynamics better than the common GARCH multiplier.

To investigate the role of volatility feedback, we use the values of AIC in Table 3 to compare the JDMAI with the JDSI model. The comparison of these alternative volatility feedback mechanisms allows us to investigate whether the superior performance of the JDMAI relative to the JDAI model is due to the presence of a common source of time-variation or a volatility feedback in the jump component. For robustness, the comparison is performed under each GARCH specification. The goodness-of-fit tests show that on average the JDSI performs as well as the JDMAI model. Each type of model exhibits a somewhat better performance over its rival model in about 50 percent of the cases. We conjecture therefore that volatility feedback in the jump structure of equity returns is an important feature in matured and emerging markets. Whether this volatility feedback is effectuated through a common or separate factor appears to be non-essential for the model's aggregate performance.

To formally explore the volatility feedback mechanism using lagged returns, we use LR tests to compare the JDSI with the nested JDAI models. According to Table 3, these tests show that, at a 5 percent significancy level, the JDAI is rejected in favor of the JDSI in 19 
cases out of the 27 comparisons. Except for China and Taiwan, we find similar results when we use the absolute value of lagged changes in the exchange rate vis-à-vis the US dollar as the measure of volatility. A drawback of currency returns as an information variable is however the fact that its predictive power is contingent on the prevailing exchange rate regime in the emerging market. For example, in the case of China, we see that the lagged currency returns do not contribute significantly, which may be attributed to the non-convertibility and fixed exchange rate policy.

Overall, these findings suggest that, given an asymmetric GARCH specification, a jump structure with time-varying jump intensity and volatility feedback provides the best fit for asset returns in mature and emerging markets.

\subsection{Parameter estimates}

To obtain further insight in the time-variation of the jump intensity, we present the parameter estimates of the JDAI-NG model in Table 4. We observe that 26 out of the 27 estimates of the parameters of the autoregressive jump intensity, $\lambda_{0}, \rho$, and $\gamma_{1}$, are statistically significant at the 5 percent level. For most EAM and the US, the estimated values for $\rho$ are relatively high, indicating clustering in the arrival rate of jumps. The result for the US index returns is broadly agreeable with the finding in Maheu and McCurdy (2004). In addition, the estimates for $\gamma_{1}$ show that the jumps in most EAM are more predictable than in the US. In particular, with a higher estimated value of 0.7487 for the parameter $\gamma_{1}$, the revisions in the conditional forecasts of the jump probabilities play a more important role for the US as compared to the EAM.

[Insert Table 4 about here]

Figure 4 displays the time-series of the conditional jump intensity for the EAM and the US. In all nine countries, the arrival rate of jumps exhibit significant changes over time. We 
observe, however, that the arrival rates follow notably different paths among the EAM. For China, India, and Taiwan, the peaks in the arrival rate of jumps do not appear to be related to the Asian crisis.

\section{[Insert Figure 4 about here]}

In Table 5, we present the parameter estimates of the JDMAI-NG model. For this extended model, we find that the introduction of a volatility feedback through a common GARCH multiplier has an adverse effect on the significancy of the coefficients of the jump intensity, $\rho$ and $\gamma_{1}$. More specifically, at 5 percent level, half of these coefficients (9 out of 18) are insignificant under the JDMAI-NG model, while the JDAI-NG exhibits only one insignificant coefficient out of 18 . We also note that, for all equity markets, the common scale factor, $h_{t}$, has an increasing impact on the jump variability parameter, $\delta$. Since under the JDMAI-NG model the variation of the jump component includes the product of $h_{t}$ and $\delta^{2}$, a higher $\delta$ does not necessarily imply that jumps vary more under a common GARCH multipier. In addition, we also observe that all the estimated values for $\delta$ in the EAM (except Taiwan) are higher than the 0.9624 in the US. When comparing the volatility asymmetry parameter, $\theta$, in Table 5 with that of the pure GARCH models in Table 2, we observe that incorporating jumps in the volatility leads to an substantial increase in the value of this parameter across all equity markets. This result indicates that the conditional volatility not only responds asymmetrically to normal innovations, but also to jump shocks.

\section{[Insert Tables 5 about here]}

Table 6 provides the parameter estimates for JDSI-NG model. We see that the separate state variable in the form of absolute value of the equity returns negatively affects the significancy of the constant component of the jump intensity $\left(\lambda_{0}\right)$, but has less unfavorable effects on the coefficients $\rho$ and $\gamma_{1}$. The volatility feedback parameter, $\gamma_{2}$, is statistically significant 
at 5 percent level in all equity markets, except Philippines. We observe that, with a value of 0.5460 for $\gamma_{2}$, the return has more predictive power in Indonesia. As with the JDMAI-NG, we note that all the JDSI-NG estimated values for $\delta$ in the EAM are higher than in the US and the estimates for $\theta$ indicate asymmetric responses to jump shocks. In contrast to the JDMAI-NG, we find that, for the JDSI-NG, most of estimates of the skewness parameters, $\phi$, are statistically significant at 5 percent level. The time-varying jump intensity parameter, $\lambda_{t}$, identifies a relatively high arrival rate or, equivalently, ex ante probability of jumps in all the equity markets. The highest arrival rate is recorded in Taiwan, where the JDSI-NG model assigns on average a 22.09 percent probability of a jump in the returns. The parameter $\lambda_{t}$ can also be interpreted as the unbiased forecasts for $E\left[N_{t} \mid I_{t}\right]$ and can be used to examine the model's ability to forecast jumps. From the estimates for $\lambda_{t}$ and $E\left[N_{t} \mid I_{t}\right]$ in tables 4 and 6 , we note that on average the forecast errors are lower for the JDSI-NG as compared to the JDAI-NG model. This result indicates that the absolute value of equity returns can help predict the number of jumps in equity markets.

\section{[Insert Tables 6 about here]}

In Table 7, we present the variance decomposition, skewness, and kurtosis of the index returns implied by the JDSI-NG model. Consistent with the summary statistics, we find that on average the total variation of the index returns is higher in the EAM as compared to the US. The results show that the jump component contributes substantially to the total variation in EAM and US equity returns. For all the Asian markets, jumps account for more than the 14.28 percent of the total variation of the index returns recorded in the US. We note that this high contribution is not artificially induced by the volatility feedback in the jump component since we find similar results for the JDAI-NG models. We also note that it is not only attributable to the crash in the Asian markets because we observe high contributions of the jump component before and after the crisis period and in equity markets that have 
not been affected significantly by the crisis. The impact of jumps on the total variation is particularly high in the EAM, with the highest being 44.47 percent in Indonesia, followed by 43.35 percent in China. The high contribution of the jump volatility in the EAM is primarily due to the relatively high variability of the jump size, $\delta$. Consistent with the literature on stochastic volatility, we observe that although the jump component contributes significantly to the total variation in the EAM and US index returns, it is not as volatile as the diffusion component.

\section{[Insert Table 7 here]}

We observe that jumps have an notable impact on the skewness of index returns in matured and emerging markets. The model-implied skewness in Table 7 is positive in most EAM and negative in the US, which is in accord with the sample skewness in Table 1. However, the size of model-implied skewness cannot match that of the sample skewness. The drawback of the extended GARCH-Jump models in capturing the size of the skewness can be ascribed to the way the compound Poisson process builds asymmetry by using one mean shift parameter instead of two decay parameters. We also infer from the model-implied kurtosis in Table 7 that the JDSI-NG models can capture the stylized feature of fatter tails for all the markets. Consistent with the sample kurtosis, we find that the implied kurtosis in the EAM (except India) is higher than in US. In addition, the sub-sample results provide evidence that supports structural changes in the tail behavior of the Asian asset returns, which coincides with the findings in Quintos, Fan, and Philips (2001). We note, however, that the model-implied kurtosis cannot match the high statistical kurtosis in Table 1. For the US and EAM-5, the model-implied kurtosis substantially understates the sample kurtosis. For example, the model-implied kurtosis for Malaysia is 9.3353, which is significantly lower than the value of 24.2447 for the sample kurtosis. Such a mismatch can be attributed to the relatively fast decay rates of the tail probabilities under the compound Poisson process with normally distributed jump sizes. 


\section{Conclusion}

In this paper, we have proposed asymmetric GARCH-Jump models that synthesize timevarying autoregressive jump intensities and volatility feedback in the jump component. The first model is an extension of Duan, Ritchken, and Sun (2005a, 2005b), where volatility feedback is generated by a common GARCH multiplier that induces time-variation in both the diffusion and jump component. This extension allows for two sources of time-variation in the jump component, namely, the common GARCH multiplier and the separate autoregressive arrival rate of jumps. In the second model, we extend the Maheu and McCurdy (2004) specification by allowing the jump intensity to be both autoregressive and dependent on the return volatility or its proxy. Hence, the contribution of the diffusion and jump component in the total variation of the equity returns is fully separable. To obtain non-affine jump intensities, we choose the absolute value of the equity return as a measure of return volatility. Alternatively, to account for the specific circumstances arising in the emerging markets, we also employed the lagged changes in the exchange rate vis-à-vis the US dollar as a proxy for return volatility. We have applied the extended models to index returns in both the US and emerging Asian equity markets.

Both extended GARCH-Jump models incorporate jumps in the returns and volatilities, allow conditional volatility to respond asymmetrically to both normal innovations and jump shocks, and generate stochastic volatility from two different sources: the GARCH effects and the arrival rate of jumps. We compare the two extended models to examine whether volatility feedback through a common GARCH multiplier in the jump component or a separate measure of return volatility in the jump intensity is more suitable to describe the return dynamics. We estimate several special cases to assess the importance of each model's component and to determine which jump structure provides the best fit. We also investigate whether the mixed GARCH-Jump models can capture the essential features in the emerging Asian equity markets, covering the periods before, during and after the Asian crisis. 
We find that the jump structures with autoregressive jump intensity and volatility feedback in the jump component provide a better fit for the dynamics of the equity returns in the US and most of the emerging markets. In comparing the extended GARCH-Jump models, the goodness-of-fit tests indicate that volatility feedback through a separate measure of volatility in the jump intensity performs as well as the common GARCH multiplier. However, at the individual parameter level, we find that the autoregressive component of the arrival rate is more compatible with volatility feedback in the jump intensity. For those Asian countries that were affected by the crisis, we find using the lagged changes in the exchange rate vis-à-vis the US dollar as a proxy for volatility provide us with similar results as the absolute value of equity returns. Across all equity markets, we find that the return volatility responds asymmetrically to jump shocks.

The extended GARCH-Jump models can also capture the distinguishing features in emerging equity markets. Consistent with the literature, the results show that the volatility in the Asian emerging markets is much higher than that of the US. The high volatilities are accompanied by negative returns even long after the Asian crisis. Furthermore, in comparison to the US, the leverage effect of normal shocks is less, jumps play a more predominant role, returns are positively skewed, and the model-implied kurtosis is substantially higher in these emerging markets. 


\section{Appendix}

The ex-post probability of jumps, $E\left[N_{t} \mid I_{t}\right]$, is defined by Maheu and McCurdy (2004) as

$$
E\left[N_{t} \mid I_{t}\right]=\sum_{j=0}^{\infty} j P\left(N_{t}=j \mid I_{t}\right)
$$

where $P\left(N_{t}=j \mid I_{t}\right)$ is the ex post inference on $N_{t}$ given the time $t$ information,

$$
P\left(N_{t}=j \mid I_{t}\right)=\frac{f\left(r_{t} \mid N_{t}=j, I_{t-1}\right) P\left(N_{t}=j \mid I_{t-1}\right)}{f\left(r_{t} \mid I_{t-1}\right)}
$$

$r_{t}$ is the lagged index return, $f\left(r_{t} \mid N_{t}=j, I_{t-1}\right)$ is the probability density function conditional on $j$ jumps and information set $I_{t-1}$, and $f\left(r_{t} \mid I_{t-1}\right)$ is the likelihood function conditional on the information set $I_{t-1}$,

$$
f\left(r_{t} \mid I_{t-1}\right)=\sum_{j=0}^{\infty} f\left(r_{t} \mid N_{t}=j, I_{t-1}\right) P\left(N_{t}=j \mid I_{t-1}\right)
$$

The conditional probability density function, $f\left(r_{t} \mid N_{t}=j, I_{t-1}\right)$, is given by

$$
f\left(r_{t} \mid N_{t}=j, I_{t-1}\right)=\frac{1}{\sqrt{2 \pi h_{t}\left(1+j \delta^{2}\right)}} \exp \left(-\frac{\left(r_{t}-\mu+\sqrt{h_{t}}\left(\lambda_{t} \phi-j \phi\right)\right)^{2}}{2 h_{t}\left(1+j \delta^{2}\right)}\right)
$$

and

$$
f\left(r_{t} \mid N_{t}=j, I_{t-1}\right)=\frac{1}{\sqrt{2 \pi\left(h_{t}+j \delta^{2}\right)}} \exp \left(-\frac{\left(r_{t}-\mu+\lambda_{t} \phi-j \phi\right)^{2}}{2\left(h_{t}+j \delta^{2}\right)}\right)
$$

for the JDMAI and JDSI model, respectively. 


\section{References}

Aggarwal, R., C. Inclan, and R. Leal, 1999, Volatility in Emerging Stock Markets, Journal of Financial and Quantitative Analysis, 34, 33-55.

Bates, D., 2000, Post-' 87 Crash Fears in the S\&P 500 Futures Option Market, Journal of Econometrics 94, 181-238.

Bekaert, G. and C.R. Harvey, 1997, Emerging Equity Market Volatility, Journal of Financial Economics 43, 29-77.

Bekaert, G. and C.R. Harvey, 2002, Research in Emerging Markets Finance: Looking to the Future, Emerging Markets Review 3, 429-448.

Bekaert, G. and G. Wu, 2000, Asymmetric Volatility and Risk in Equity Markets, The Review of Financial Studies 13, 1-42.

Chernov, M., A. Gallant, E. Ghysels, and G. Tauchen, 1999, A New Class of Stochastic Volatility Models with Jumps: Theory and Estimation,Working Paper, CIRANO, 99s48, Montreal.

Das, S.R., and R. K. Sundaram, 1999, Of Smiles and Smirks: A Term Structure Perspective, Journal of Financial and Quantitative Analysis 34, 211-239.

Ding, Z., C. Granger, and R. Engle, 1993, A Long Memory Property of Stock Market Returns and a New Model, Journal of Empirical Finance 1, 83-106.

Duan, J., 1997, Augmented $\operatorname{GARCH}(p, q)$ Processs and its Diffusion Limit, Journal of Econometrics 79, 97-127.

Duan, J., P. Ritchken, and Z. Sun, 2005a, Jump Starting GARCH: Pricing and Hedging Options with Jumps in Returns and Volatilities, Working Paper, University of Toronto and Case Western Reserve University.

Duan, J., P. Ritchken, and Z. Sun, 2005b, Approximating GARCH-Jump Models, Jump-Diffusion Processes, and Option Pricing, forthcoming, Mathematical Finance.

Duan, J. and H. Zhang, 2001, Pricing Hang Seng Index Options around the Asian Financial Crisis - A GARCH approach, Journal of Banking and Finance 25, 1989-2014.

Duffie, D., J. Pan, and K. Singleton, 2000, Transform Analysis and Option Pricing for Affine Jump-Diffusions, Econometrica 68, 1343-1376.

Eraker, B., 2004, Do Stock Prices and Volatility Jump? Reconciling Evidence from Spot and Option Prices, Journal of Finance 59, 1367-1403.

Eraker, B., M.S. Johannes, and N.G. Polson, 2003, The Impact of Jumps in Returns and Volatility, Journal of Finance 53, 1269-1300. 
Harvey, C.R., 1995, Predictable Risk and Returns in Emerging Markets, The Review of Financial Studies 8, 773-816.

Heston, S.L., and S. Nandi, 2000, A Closed-Form GARCH Option Valuation Model, Review of Financial Studies 13, 585-625.

Jorion, P., 1988, On Jump Processes in the Foreign Exchange and Stock Markets, Review of Financial Studies 1, 427-445.

Kaminsky, G., and S. Schmukler, 1999, What Triggers Market Jitters? A Chronicle of the Asian Crisis, Journal of International Money and Finance 18, 537-560.

Maheu J.M., and T.H. McCurdy, 2004, News Arrival, Jump Dynamics, and Volatility Components for Individual Stock Returns, Journal of Finance 59, 755-793.

Maroney N., A. Naka, and T. Wansi, 2004, Changing Risk, Return, and Leverage: The 1997 Asian Financial Crisis, Journal of Financial and Quantitative Analysis 39, 143-166.

Pan, J., 2002, The Jump-Risk Premia implicit in Options: Evidence from an Integrated Time-Series Study, Journal of Financial Economics 63, 3-50.

Quintos, C., S. Fan, and P.C. Philips, 2001, Structural Change Tests in Tail Behavior and the Asian Crisis, Review of Economic Studies 68, 633-663.

Wu, G., 2001, The Determinants of Asymmetric Volatility, The Review of Financial Studies 14, 837-859. 


\section{Table 1}

Summary Statistics of Equity Returns and Foreign Currency Returns

\begin{tabular}{lccccccccc}
\hline \multicolumn{3}{l}{ Panel A: Whole Period } & & & & & & & \\
Obs & $\underline{\mathbf{U S}}$ & $\underline{\mathbf{C H}}$ & $\underline{\mathbf{I N}}$ & $\underline{\mathbf{I D}}$ & $\underline{\mathbf{K R}}$ & $\underline{\mathbf{M Y}}$ & $\underline{\mathbf{P H}}$ & $\underline{\mathbf{T W}}$ & $\underline{\mathbf{T H}}$ \\
Mean & 1788 & 1804 & 1801 & 1815 & 1784 & 1781 & 1810 & 1788 & 1823 \\
Min & 0.0003 & 0.0005 & -0.0002 & -0.0008 & -0.0002 & -0.0004 & -0.0009 & -0.0002 & -0.0010 \\
Max & -0.0711 & -0.1019 & -0.0787 & -0.4085 & -0.2156 & -0.2382 & -0.0971 & -0.1108 & -0.1505 \\
Std & 0.0557 & 0.0870 & 0.0922 & 0.2543 & 0.2679 & 0.2295 & 0.2026 & 0.0754 & 0.1658 \\
Skewness & -0.0120 & 0.0173 & 0.0165 & 0.0368 & 0.0307 & 0.0230 & 0.0187 & 0.0195 & 0.0259 \\
Kurtosis & 6.1418 & -0.2802 & 0.0106 & -0.8631 & 0.3049 & 0.7105 & 1.0928 & 0.0415 & 0.5885 \\
& & & & & & & & &
\end{tabular}

Panel B: 1st sub-period

\begin{tabular}{lccccccccc}
\hline & $\underline{\mathbf{U S}}$ & $\underline{\mathbf{C H}}$ & $\underline{\mathbf{I N}}$ & $\underline{\mathbf{I D}}$ & $\underline{\mathbf{K R}}$ & $\underline{\mathbf{M Y}}$ & $\underline{\mathbf{P H}}$ & $\underline{\mathbf{T W}}$ & $\underline{\mathbf{T H}}$ \\
Obs & 507 & 510 & 509 & 546 & 587 & 524 & 516 & 574 & 515 \\
Mean & 0.0010 & 0.0018 & 0.0002 & 0.0000 & -0.0015 & -0.0001 & -0.0004 & 0.0004 & -0.0020 \\
Min & -0.0313 & -0.1019 & -0.0787 & -0.0768 & -0.0881 & -0.0347 & -0.0583 & -0.0703 & -0.0776 \\
Max & 0.0269 & 0.0802 & 0.0629 & 0.0392 & 0.0765 & 0.0276 & 0.0468 & 0.0652 & 0.0649 \\
Std & 0.0076 & 0.0224 & 0.0138 & 0.0120 & 0.0168 & 0.0090 & 0.0108 & 0.0154 & 0.0169 \\
Skewness & -0.4198 & -0.5832 & 0.2878 & -0.9225 & -0.1850 & -0.1985 & -0.4010 & -0.1097 & -0.0968 \\
Kurtosis & 4.5688 & 6.0953 & 6.8692 & 8.4281 & 7.5724 & 4.3320 & 6.3687 & 5.4800 & 6.0809
\end{tabular}

Panel C: 2nd sub-period

$\begin{array}{lccccccccc} & \underline{\mathbf{U S}} & \underline{\mathbf{C H}} & \underline{\mathbf{I N}} & \underline{\mathbf{I D}} & \underline{\mathbf{K R}} & \underline{\mathbf{M Y}} & \underline{\mathbf{P H}} & \underline{\mathbf{T W}} & \underline{\mathbf{T H}} \\ \text { Obs } & 630 & 635 & 629 & 599 & 540 & 623 & 632 & 533 & 637 \\ \text { Mean } & 0.0008 & 0.0000 & 0.0004 & -0.0014 & 0.0014 & -0.0010 & -0.0007 & 0.0003 & -0.0006 \\ \text { Min } & -0.0711 & -0.0828 & -0.0672 & -0.4085 & -0.2156 & -0.2382 & -0.0971 & -0.0705 & -0.1505 \\ \text { Max } & 0.0499 & 0.0599 & 0.0922 & 0.2543 & 0.2679 & 0.2295 & 0.1275 & 0.0686 & 0.1658 \\ \text { Std } & 0.0123 & 0.0155 & 0.0173 & 0.0585 & 0.0431 & 0.0355 & 0.0244 & 0.0192 & 0.0358 \\ \text { Skewness } & -0.4406 & -0.2191 & 0.2522 & -0.5963 & 0.3830 & 0.6193 & 0.0335 & 0.1776 & 0.6525 \\ \text { Kurtosis } & 7.0671 & 6.8022 & 5.2634 & 10.4326 & 8.6351 & 12.0711 & 5.6447 & 4.5864 & 5.7357\end{array}$

Panel D: 3rd sub-period

\begin{tabular}{lccccccccc} 
& $\underline{\mathbf{U S}}$ & $\underline{\mathbf{C H}}$ & $\underline{\mathbf{I N}}$ & $\underline{\mathbf{I D}}$ & $\underline{\mathbf{K R}}$ & $\underline{\mathbf{M Y}}$ & $\underline{\mathbf{P H}}$ & $\underline{\mathbf{T W}}$ & $\underline{\mathbf{T H}}$ \\
Obs & 651 & 659 & 663 & 670 & 657 & 634 & 662 & 661 & 671 \\
Mean & -0.0008 & -0.0001 & -0.0009 & -0.0009 & -0.0005 & -0.0001 & -0.0014 & -0.0010 & -0.0007 \\
Min & -0.0601 & -0.0612 & -0.0698 & -0.0897 & -0.1268 & -0.0690 & -0.0788 & -0.1108 & -0.0815 \\
Max & 0.0557 & 0.0870 & 0.0716 & 0.1058 & 0.0932 & 0.0562 & 0.2026 & 0.0754 & 0.0690 \\
Std & 0.0142 & 0.0140 & 0.0175 & 0.0224 & 0.0278 & 0.0134 & 0.0172 & 0.0228 & 0.0198 \\
Skewness & 0.1515 & 0.3661 & -0.3031 & -0.3118 & -0.3043 & -0.3517 & 3.8325 & 0.0602 & -0.1781 \\
Kurtosis & 4.4706 & 6.8050 & 4.7388 & 5.0481 & 4.7539 & 6.3817 & 45.1850 & 4.1049 & 4.6369 \\
\hline
\end{tabular}


Table 1 (continued)

\section{Summary Statistics of Equity Returns and Foreign Currency Returns}

\begin{tabular}{lcccccccc}
\hline \multicolumn{3}{l}{ Panel E: Currency Returns } & & & & & & \\
Obs & $\underline{\mathbf{C H}}$ & $\underline{\mathbf{I N}}$ & $\underline{\mathbf{I D}}$ & $\underline{\mathbf{K R}}$ & $\underline{\mathbf{M Y}}$ & $\underline{\mathbf{P H}}$ & $\underline{\mathbf{T W}}$ & $\underline{\mathbf{T H}}$ \\
Mean & 1804 & 1801 & 1815 & 1784 & 1781 & 1810 & 1788 & 1823 \\
Min & 0.0000 & -0.00024 & -0.00077 & -0.00026 & -0.00025 & -0.00039 & -0.00015 & -0.00030 \\
Max & -0.0050 & -0.06151 & -0.23936 & -0.13645 & -0.06773 & -0.12632 & -0.04747 & -0.11905 \\
Std & 0.0050 & 0.04705 & 0.20416 & 0.19795 & 0.07309 & 0.11096 & 0.02621 & 0.06245 \\
Skewness & -0.0002 & 0.00331 & 0.02330 & 0.01186 & 0.00704 & 0.00764 & 0.00307 & 0.00842 \\
Kurtosis & 621.5013 & -2.97400 & -1.22321 & 0.68159 & 0.30790 & -1.22480 & -2.99751 & -1.58348 \\
\hline
\end{tabular}

Note: This table presents summary statistics for returns on the S\&P 500 index (US), eight emerging Asian stock market indices, and eight Asian currencies. The Asian markets are China (CH), India (IN), Indonesia (ID), Korea (KR), Malaysia (MY), Philippines (PH), Taiwan (TW), and Thailand (TH). All returns are denominated in US dollar terms. The exchange rates are defined as the value of one unit of each Asian currency in terms of the U.S. dollar. Excluded are holidays (zero returns) for the US and Asian markets. The sample covers the period from 7/5/95 through 8/7/02. The sample period for each country is divided into three sub-periods:

- 1st sub-period: US, CH, IN, TH 7/5/95-7/2/97; ID 7/5/95-8/14/97; KR 7/5/95-11/7/97; MY 7/5/95-

7/14/97; PH 7/5/95-7/11/97; TW 7/5/95-10/17/97

- 2nd sub-period: US 7/3/97-12/31/99; CH, IN, TH 7/3/97-12/30/99; ID 8/15/97-12/30/99; KR 11/10/9712/30/99; MY 7/15/97-12/30/99; PH 7/14/97-12/29/99; TW 10/17/97-12/30/99

- 3rd sub-period: 1/3/00-8/7/02 (except ID 1/4/00-8/7/02) 


\section{Table 2}

\section{Specification Tests of the GARCH, NGARCH, and PGARCH Models}

$\underline{\text { US }} \quad \underline{\mathrm{CH}} \quad \underline{\mathrm{IN}} \quad \underline{\text { ID }} \quad \underline{\text { KR }} \quad \underline{\text { MY }} \quad \underline{\text { PH }} \quad \underline{\text { TW }} \quad \underline{\text { TH }}$

$\underline{\text { Panel A: Log Likelihood }}$

$\begin{array}{llllllllll}\text { GARCH } & 5537.87 & 4926.58 & 4923.56 & 4145.94 & 4068.37 & 4894.66 & 4988.46 & 4587.72 & 4381.76 \\ \text { NGARCH } & 5579.73 & 4927.54 & 4937.50 & 4150.84 & 4073.72 & 4908.81 & 5003.50 & 4603.99 & 4385.22 \\ \text { PGARCH } & 5579.12 & 4927.65 & 4937.33 & 4150.25 & 4073.36 & 4908.30 & 5003.19 & 4604.03 & 4385.01\end{array}$

Panel B: Akaike's Information Criterion

$\begin{array}{llllllllll}\text { GARCH } & -6.1900 & -5.4574 & -5.4631 & -4.5641 & -4.5565 & -5.4920 & -5.5077 & -5.1272 & -4.8028 \\ \text { NGARCH } & -6.2357 & -5.4574 & -5.4775 & -4.5684 & -4.5613 & -5.5068 & -5.5232 & -5.1443 & -4.8055 \\ \text { PGARCH } & -6.2350 & -5.4575 & -5.4773 & -4.5678 & -4.5609 & -5.5062 & -5.5229 & -5.1443 & -4.8053\end{array}$

\section{Panel C: Parameter Estimates NGARCH}

$\begin{array}{cccccccccc}\mu & 0.0002 & 0.0001 & 0.0002 & 0.0001 & -0.0006 & 0.0000 & -0.0006 & -0.0002 & -0.0009 \\ & (0.4340) & (0.7070) & (0.5480) & (0.9150) & (0.2660) & (0.8750) & (0.0660) & (0.6450) & (0.0420) \\ \alpha_{0} & 0.0000 & 0.0000 & 0.0000 & 0.0000 & 0.0000 & 0.0000 & 0.0000 & 0.0000 & 0.0000 \\ & (0.0090) & (0.0000) & (0.0000) & (0.0000) & (0.3810) & (0.0520) & (0.0000) & (0.0010) & (0.0000) \\ \alpha_{1} & 0.0710 & 0.1722 & 0.1402 & 0.1272 & 0.0785 & 0.1108 & 0.1616 & 0.0803 & 0.0995 \\ & (0.0000) & (0.0000) & (0.0000) & (0.0000) & (0.0000) & (0.0000) & (0.0000) & (0.0000) & (0.0000) \\ \beta & 0.8965 & 0.7400 & 0.7273 & 0.8818 & 0.9229 & 0.8854 & 0.8413 & 0.8725 & 0.8898 \\ & (0.0000) & (0.0000) & (0.0000) & (0.0000) & (0.0000) & (0.0000) & (0.0000) & (0.0000) & (0.0000) \\ \theta & 0.0110 & 0.0015 & 0.0062 & 0.0033 & 0.0047 & 0.0044 & 0.0038 & 0.0098 & 0.0032 \\ & (0.0000) & (0.0310) & (0.0000) & (0.0000) & (0.0000) & (0.0000) & (0.0000) & (0.0000) & (0.0000)\end{array}$

Note: This table presents specification tests for the GARCH, NGARCH, and PGARCH models applied to the S\&P 500 index (US) and eight emerging Asian stock market indices denominated in US dollar terms. The log likelihoods are used to compare the asymmetric NGARCH and PGARCH models with the nested GARCH model. For the comparison of the non-nested NGARCH and PGARCH models, we report the Akaike's information criterion for the specification tests. In addition, we report the parameter estimates of the NGARCH models. (CH-China, IN-India, ID-Indonesia, KR-Korea, MY-Malaysia, PH-Philippines, TW-Taiwan, TH-Thailand) 


\section{Table 3}

\section{Specification Tests of the Alternative GARCH-Jump models}

\begin{tabular}{|c|c|c|c|c|c|c|c|c|c|}
\hline & $\underline{\mathrm{US}}$ & $\underline{\mathrm{CH}}$ & $\underline{\text { IN }}$ & $\underline{\text { ID }}$ & $\underline{\mathrm{KR}}$ & $\underline{\text { MY }}$ & $\underline{\mathbf{P H}}$ & $\underline{T W}$ & $\underline{\mathbf{T H}}$ \\
\hline \multirow[t]{2}{*}{ JDMAI-PG } & 5608.89 & 5030.92 & 4990.39 & 4270.91 & 4105.24 & 4973.42 & 5129.75 & 4625.14 & 4454.16 \\
\hline & $(-6.2627)$ & $(-5.5664)$ & $(-5.5307)$ & $(-4.6952)$ & $(-4.5911)$ & $(-5.5737)$ & $(-5.6572)$ & $(-5.1623)$ & $(-4.8757)$ \\
\hline \multirow[t]{2}{*}{ JDMAI-NG } & 5615.14 & 5033.39 & 4985.67 & 4281.29 & 4106.30 & 4982.02 & 5129.77 & 4616.73 & 4456.39 \\
\hline & $(-6.2697)$ & $(-5.5692)$ & $(-5.5255)$ & $(-4.7067)$ & $(-4.5923)$ & $(-5.5834)$ & $(-5.6572)$ & $(-5.1529)$ & $(-4.8781)$ \\
\hline \multirow[t]{2}{*}{ JDMAI-G } & 5583.44 & 5028.13 & 4979.00 & 4266.85 & 4088.93 & 4966.24 & 5100.05 & 4612.32 & 4436.87 \\
\hline & $(-6.2354)$ & $(-5.5644)$ & $(-5.5192)$ & $(-4.6918)$ & $(-4.5739)$ & $(-5.5668)$ & $(-5.6255)$ & $(-5.1491)$ & $(-4.8578)$ \\
\hline \multirow[t]{2}{*}{ JDSI-PG } & 5608.07 & 5042.21 & 4990.54 & 4250.44 & 4106.39 & 4960.31 & 5128.05 & 4639.44 & 4458.77 \\
\hline & $(-6.2607)$ & $(-5.5778)$ & $(-5.5298)$ & $(-4.6716)$ & $(-4.5912)$ & $(-5.5579)$ & $(-5.6542)$ & $(-5.1772)$ & $(-4.8796)$ \\
\hline \multirow[t]{2}{*}{ JDSI-NG } & 5614.93 & 5044.67 & 4989.07 & 4251.96 & 4112.65 & 4965.39 & 5125.83 & 4646.54 & 4460.68 \\
\hline & $(-6.2684)$ & $(-5.5806)$ & $(-5.5281)$ & $(-4.6732)$ & $(-4.5983)$ & $(-5.5636)$ & $(-5.6517)$ & $(-5.1852)$ & $(-4.8817)$ \\
\hline \multirow[t]{2}{*}{ JDSI-G } & 5583.11 & 5033.27 & 4982.92 & 4243.90 & 4098.26 & 4960.29 & 5121.57 & 4612.30 & 4446.82 \\
\hline & $(-6.2339)$ & $(-5.5690)$ & $(-5.5224)$ & $(-4.6655)$ & $(-4.5833)$ & $(-5.5590)$ & $(-5.6481)$ & $(-5.1480)$ & $(-4.8676)$ \\
\hline \multirow[t]{2}{*}{ JDSI-NG* } & N/A & 5045.19 & 4989.88 & 4259.30 & 4112.79 & 4966.07 & 5127.39 & 4646.54 & 4459.35 \\
\hline & N/A & $(-5.5811)$ & $(-5.5290)$ & $(-4.6813)$ & $(-4.5984)$ & $(-5.5644)$ & $(-5.6535)$ & $(-5.1852)$ & $(-4.8803)$ \\
\hline \multirow[t]{2}{*}{ JDM-PG } & 5605.21 & 5022.65 & 4988.99 & 4266.94 & 4099.05 & 4966.99 & 5103.44 & 4603.79 & 4450.30 \\
\hline & $(-6.2609)$ & $(-5.5595)$ & $(-5.5314)$ & $(-4.6930)$ & $(-4.5864)$ & $(-5.5688)$ & $(-5.6303)$ & $(-5.1407)$ & $(-4.8736)$ \\
\hline \multirow[t]{2}{*}{ JDM-NG } & 5604.69 & 5023.53 & 4984.79 & 4265.04 & 4098.54 & 4966.76 & 5108.38 & 4609.84 & 4452.92 \\
\hline & $(-6.2603)$ & $(-5.5605$ & $(-5.5267)$ & $(-4.6910)$ & $(-4.5858)$ & $(-5.5685)$ & $(-5.6358)$ & $(-5.1475$ & $(-4.8765)$ \\
\hline \multirow[t]{2}{*}{ JDM-G } & 5573.77 & 5015.23 & 4977.46 & 4249.38 & 4084.23 & 4952.68 & 5076.13 & 4600.27 & 4421.09 \\
\hline & $(-6.2268)$ & $(-5.5524)$ & $(-5.5197)$ & $(-4.6748)$ & $(-4.5709)$ & $(-5.5538)$ & $(-5.6012)$ & $(-5.1379)$ & $(-4.8427)$ \\
\hline \multirow[t]{2}{*}{ JDAI-PG } & 5607.94 & 5042.07 & 4990.54 & 4241.59 & 4106.38 & 4956.02 & 5117.12 & 4639.29 & 4453.16 \\
\hline & $(-6.2617)$ & $(-5.5788)$ & $(-5.5309)$ & $(-4.6629)$ & $(-4.5924)$ & $(-5.5542)$ & $(-5.6432)$ & $(-5.1782)$ & $(-4.8746)$ \\
\hline \multirow[t]{2}{*}{ JDAI-NG } & 5605.47 & 5033.03 & 4988.80 & 4245.30 & 4107.64 & 4962.19 & 5113.95 & 4644.71 & 4452.72 \\
\hline & $(-6.2589)$ & $(-5.5688)$ & $(-5.5289)$ & $(-4.6670)$ & $(-4.5938)$ & $(-5.5611)$ & $(-5.6397)$ & $(-5.1842$ & $(-4.8741)$ \\
\hline \multirow[t]{2}{*}{ JDAI-G } & 5579.97 & 5025.16 & 4977.94 & 4231.77 & 4097.21 & 4948.37 & 5106.48 & 4611.46 & 4438.78 \\
\hline & $(-6.2315)$ & $(-5.5612)$ & $(-5.5180)$ & $(-4.6532)$ & $(-4.5832)$ & $(-5.5467)$ & $(-5.6326)$ & $(-5.1482)$ & $(-4.8599)$ \\
\hline
\end{tabular}

Note: This table presents the log likelihoods and Akaike's information criterions for the JDMAI, JDSI, JDM, and JDAI models under three alternative GARCH specifications, where NG, PG, and G respectively denote the NGARCH, PGARCH, and GARCH specification. These tests are also reported for the JDSING*, which is the JDSI-NG model with the absolute value of lagged currency returns as a measure for volatility. Akaike's information criterions are in parentheses. The models are applied to the S\&P 500 index (US) and eight emerging Asian stock market indices denominated in US dollar terms. (CH-China, IN-India, ID-Indonesia, KR-Korea, MY-Malaysia, PH-Philippines, TW-Taiwan, TH-Thailand) 
Table 4

Parameter Estimates of the JDAI-NG Model

\begin{tabular}{|c|c|c|c|c|c|c|c|c|c|}
\hline & $\underline{\mathrm{US}}$ & $\underline{\mathrm{CH}}$ & $\underline{I N}$ & ID & $\underline{\mathbf{K R}}$ & $\underline{\text { MY }}$ & $\underline{\mathbf{P H}}$ & $\underline{\text { TW }}$ & $\underline{\mathbf{T H}}$ \\
\hline \multirow[t]{2}{*}{$\mu$} & 0.0001 & 0.0003 & 0.0000 & -0.0006 & -0.0007 & -0.0002 & -0.0009 & -0.0001 & -0.0009 \\
\hline & $(0.2915)$ & $(0.2136)$ & $(0.4747)$ & $(0.1262)$ & $(0.0702)$ & $(0.2683)$ & $(0.0004)$ & $(0.4334)$ & $(0.0249)$ \\
\hline \multirow{2}{*}{$\alpha_{0}$} & 0.0011 & 0.0033 & 0.0032 & 0.0026 & 0.0019 & 0.0016 & 0.0025 & 0.0009 & 0.0010 \\
\hline & $(0.0000)$ & $(0.0000)$ & $(0.0000)$ & $(0.0000)$ & $(0.0000)$ & $(0.0000)$ & $(0.0000)$ & $(0.0167)$ & $(0.0092)$ \\
\hline \multirow[t]{2}{*}{$\alpha_{1}$} & 0.0626 & 0.1362 & 0.0905 & 0.0730 & 0.0619 & 0.1176 & 0.1444 & 0.0413 & 0.0877 \\
\hline & $(0.0000)$ & $(0.0000)$ & $(0.0000)$ & $(0.0000)$ & $(0.0000)$ & $(0.0000)$ & $(0.0000)$ & $(0.0000)$ & $(0.0000)$ \\
\hline \multirow[t]{2}{*}{$\beta$} & 0.8940 & 0.6882 & 0.7999 & 0.8524 & 0.9112 & 0.8359 & 0.7784 & 0.8906 & 0.8500 \\
\hline & $(0.0000)$ & $(0.0000)$ & $(0.0000)$ & $(0.0000)$ & $(0.0000)$ & $(0.0000)$ & $(0.0000)$ & $(0.0000)$ & $(0.0000)$ \\
\hline \multirow[t]{2}{*}{$\theta$} & 0.6667 & 0.4769 & 0.5141 & 0.6293 & 0.4909 & 0.3883 & 0.2513 & 1.1152 & 0.5655 \\
\hline & $(0.0000)$ & $(0.0000)$ & $(0.0000)$ & $(0.0000)$ & $(0.0000)$ & $(0.0000)$ & $(0.0003)$ & $(0.0000)$ & $(0.0000)$ \\
\hline \multirow[t]{2}{*}{$\lambda_{0}$} & 0.0332 & 0.1401 & 0.0081 & 0.0547 & 0.0191 & 0.0461 & 0.0499 & 0.0841 & 0.0545 \\
\hline & $(0.0000)$ & $(0.0000)$ & $(0.0000)$ & $(0.0001)$ & $(0.0173)$ & $(0.0067)$ & $(0.0000)$ & $(0.0000)$ & $(0.0000)$ \\
\hline \multirow[t]{2}{*}{$\rho$} & 0.7593 & 0.2655 & 0.9449 & 0.4769 & 0.6353 & 0.2666 & 0.5109 & 0.6032 & 0.7039 \\
\hline & $(0.0000)$ & $(0.0098)$ & $(0.0000)$ & $(0.0001)$ & $(0.0000)$ & $(0.0401)$ & $(0.0000)$ & $(0.0000)$ & $(0.0000)$ \\
\hline \multirow[t]{2}{*}{$\gamma_{1}$} & 0.7487 & 0.1760 & 0.1371 & 0.4527 & 0.6097 & 0.2466 & 0.3052 & 0.2085 & 0.3844 \\
\hline & $(0.0000)$ & $(0.0102)$ & $(0.0151)$ & $(0.0001)$ & $(0.0000)$ & $(0.0601)$ & $(0.0375)$ & $(0.0219)$ & $(0.0473)$ \\
\hline \multirow[t]{2}{*}{$\phi$} & -0.0110 & 0.0004 & 0.0020 & -0.0100 & 0.0017 & -0.0028 & -0.0019 & 0.0036 & 0.0061 \\
\hline & $(0.0000)$ & $(0.4193)$ & $(0.2337)$ & $(0.0270)$ & $(0.4102)$ & $(0.2621)$ & $(0.2345)$ & $(0.0640)$ & $(0.0196)$ \\
\hline \multirow[t]{2}{*}{$\delta$} & 0.0090 & 0.0240 & 0.0223 & 0.0570 & 0.0471 & 0.0304 & 0.0291 & 0.0209 & 0.0278 \\
\hline & $(0.0000)$ & $(0.0000)$ & $(0.0000)$ & $(0.0000)$ & $(0.0000)$ & $(0.0000)$ & $(0.0000)$ & $(0.0000)$ & $(0.0000)$ \\
\hline \multirow{2}{*}{$\begin{array}{l}\lambda_{\mathrm{t}} \\
E\left[N_{t} \mid I_{t}\right]\end{array}$} & 0.1194 & 0.1904 & 0.1447 & 0.102 & 0.0513 & 0.0207 & 0.1005 & 0.2152 & 0.1841 \\
\hline & 0.1135 & 0.1895 & 0.144 & 0.0991 & 0.0507 & 0.0219 & 0.0982 & 0.2128 & 0.1846 \\
\hline
\end{tabular}

Note: This table presents estimation results of the JDAI-NG model for the S\&P 500 index (US) and eight emerging Asian stock market indices denominated in US dollar terms. The parameters are estimated using the maximum-likelihood method. The probability density functions are provided in the Appendix. The $p$ values are reported in parentheses. $\lambda_{\mathrm{t}}$ is the average value of the conditional arrival rate or, equivalently, exante probability of jumps and $E\left[N_{t} \mid I_{t}\right]$ is the ex-post probability of jumps, which is described in the Appendix. (CH-China, IN-India, ID-Indonesia, KR-Korea, MY-Malaysia, PH-Philippines, TW-Taiwan, TH-Thailand) 
Table 5

Parameter Estimates of the JDMAI-NG Model

\begin{tabular}{|c|c|c|c|c|c|c|c|c|c|}
\hline & $\underline{\text { US }}$ & $\underline{\mathrm{CH}}$ & $\underline{\text { IN }}$ & $\underline{\text { ID }}$ & $\underline{\mathbf{K R}}$ & $\underline{\mathbf{M Y}}$ & $\underline{\mathbf{P H}}$ & $\underline{\text { TW }}$ & $\underline{\mathbf{T H}}$ \\
\hline \multirow[t]{2}{*}{$\mu$} & 0.0002 & 0.0002 & 0.0001 & 0.0001 & -0.0006 & -0.0001 & -0.0007 & -0.0002 & -0.0008 \\
\hline & $(0.1710)$ & $(0.2267)$ & (0.3815) & $(0.4222)$ & (0.1208) & $(0.4106)$ & $(0.0097)$ & $(0.3222)$ & $(0.0384)$ \\
\hline \multirow[t]{2}{*}{$\alpha_{0}$} & 0.0014 & 0.0037 & 0.0032 & 0.0033 & 0.0019 & 0.0021 & 0.0026 & 0.0025 & 0.0019 \\
\hline & $(0.0000)$ & $(0.0000)$ & $(0.0000)$ & $(0.0000)$ & $(0.0000)$ & $(0.0000)$ & $(0.0000)$ & $(0.0000)$ & $(0.0000)$ \\
\hline \multirow[t]{2}{*}{$\alpha_{1}$} & 0.0478 & 0.1248 & 0.0889 & 0.0801 & 0.0579 & 0.0859 & 0.1134 & 0.0413 & 0.0661 \\
\hline & $(0.0000)$ & $(0.0000)$ & $(0.0000)$ & $(0.0000)$ & $(0.0000)$ & $(0.0000)$ & $(0.0000)$ & $(0.0004)$ & $(0.0000)$ \\
\hline \multirow[t]{2}{*}{$\beta$} & 0.8316 & 0.6928 & 0.8190 & 0.7922 & 0.9152 & 0.8096 & 0.7627 & 0.9229 & 0.8634 \\
\hline & $(0.0000)$ & $(0.0000)$ & $(0.0000)$ & $(0.0000)$ & $(0.0000)$ & $(0.0000)$ & $(0.0000)$ & $(0.0000)$ & $(0.0000)$ \\
\hline \multirow[t]{2}{*}{$\theta$} & 1.4772 & 0.3699 & 0.3899 & 0.5443 & 0.4719 & 0.5502 & 0.3258 & 0.5136 & 0.5477 \\
\hline & $(0.0000)$ & $(0.0003)$ & $(0.0000)$ & $(0.0001)$ & $(0.0001)$ & $(0.0000)$ & $(0.0012)$ & $(0.0008)$ & $(0.0000)$ \\
\hline \multirow[t]{2}{*}{$\lambda_{0}$} & 0.0110 & 0.1033 & 0.0182 & 0.0005 & 0.0241 & 0.0007 & 0.0007 & 0.0076 & 0.1481 \\
\hline & $(0.0000)$ & $(0.2116)$ & $(0.0000)$ & $(0.0150)$ & $(0.0601)$ & $(0.0652)$ & $(0.0525)$ & $(0.0286)$ & $(0.0001)$ \\
\hline \multirow[t]{2}{*}{$\rho$} & 0.7285 & 0.4379 & 0.7909 & 0.8979 & 0.5876 & 0.8962 & 0.8966 & 0.1054 & 0.0000 \\
\hline & $(0.0000)$ & $(0.2682)$ & $(0.0000)$ & $(0.0000)$ & $(0.0048)$ & $(0.0000)$ & $(0.0000)$ & $(0.3785)$ & $(0.5000)$ \\
\hline \multirow[t]{2}{*}{$\gamma_{1}$} & 0.3636 & 0.0000 & 0.0246 & 0.0127 & 0.3494 & 0.0183 & 0.0093 & 0.5001 & 0.1104 \\
\hline & $(0.0096)$ & $(0.4996)$ & (0.3069) & $(0.1771)$ & $(0.0376)$ & $(0.0933)$ & $(0.2860)$ & $(0.0011)$ & $(0.0693)$ \\
\hline \multirow[t]{2}{*}{$\phi$} & -0.0169 & 0.0004 & 0.0042 & -0.0009 & 0.0022 & 0.0010 & 0.0005 & -0.0294 & 0.0062 \\
\hline & $(0.0001)$ & $(0.4093)$ & $(0.1342)$ & $(0.3606)$ & $(0.3172)$ & $(0.2787)$ & (0.3914) & $(0.0000)$ & $(0.0028)$ \\
\hline \multirow[t]{2}{*}{$\delta$} & 0.9624 & 2.1813 & 2.1092 & 2.3111 & 1.9666 & 1.9849 & 2.1225 & 0.5405 & 1.9605 \\
\hline & $(0.0079)$ & $(0.0000)$ & $(0.0000)$ & $(0.0000)$ & $(0.0000)$ & $(0.0000)$ & $(0.0000)$ & $(0.0414)$ & $(0.0000)$ \\
\hline
\end{tabular}

Note: This table reports estimation results for the JDMAI model under the NGARCH specification for the S\&P 500 index (US) and eight emerging Asian stock market indices denominated in US dollar terms. The parameters are estimated using the maximum-likelihood method. The probability density functions are provided in the Appendix. The $p$-values are reported in parentheses. (CH-China, IN-India, ID-Indonesia, KR-Korea, MY-Malaysia, PH-Philippines, TW-Taiwan, TH-Thailand) 


\section{Table 6}

\section{Parameter Estimates of the JDSI-NG Model}

\begin{tabular}{|c|c|c|c|c|c|c|c|c|c|}
\hline & $\underline{\mathrm{US}}$ & $\underline{\mathrm{CH}}$ & $\underline{\text { IN }}$ & $\underline{\text { ID }}$ & $\underline{\mathbf{K R}}$ & $\underline{\text { MY }}$ & $\underline{\mathbf{P H}}$ & $\underline{\text { TW }}$ & $\underline{\mathbf{T H}}$ \\
\hline \multirow[t]{2}{*}{$\mu$} & 0.0002 & -0.0001 & 0.0000 & -0.0004 & -0.0007 & -0.0002 & -0.0008 & -0.0001 & -0.0007 \\
\hline & $(0.2256)$ & $(0.4307)$ & (0.4470) & $(0.1790)$ & $(0.0866)$ & $(0.2873)$ & $(0.0026)$ & $(0.3784)$ & $(0.0440)$ \\
\hline \multirow[t]{2}{*}{$\alpha_{0}$} & 0.0014 & 0.0053 & 0.0032 & 0.0027 & 0.0019 & 0.0012 & 0.0034 & 0.0019 & 0.0024 \\
\hline & $(0.0000)$ & $(0.0000)$ & (0.0000) & $(0.0000)$ & $(0.0000)$ & $(0.0000)$ & $(0.0000)$ & $(0.0022)$ & $(0.0000)$ \\
\hline \multirow[t]{2}{*}{$\alpha_{1}$} & 0.0527 & 0.1401 & 0.0838 & 0.0735 & 0.0601 & 0.0863 & 0.1565 & 0.0472 & 0.0999 \\
\hline & $(0.0000)$ & $(0.0000)$ & (0.0000) & $(0.0000)$ & $(0.0000)$ & $(0.0000)$ & $(0.0000)$ & $(0.0000)$ & $(0.0000)$ \\
\hline \multirow[t]{2}{*}{$\beta$} & 0.8307 & 0.5291 & 0.8134 & 0.8509 & 0.9120 & 0.8930 & 0.7017 & 0.8158 & 0.8066 \\
\hline & $(0.0000)$ & $(0.0000)$ & (0.0000) & $(0.0000)$ & $(0.0000)$ & $(0.0000)$ & $(0.0000)$ & $(0.0000)$ & $(0.0000)$ \\
\hline \multirow[t]{2}{*}{$\theta$} & 0.3621 & 0.7033 & 0.4996 & 0.5834 & 0.5053 & 0.3488 & 0.2909 & 0.5103 & 0.5736 \\
\hline & $(0.0000)$ & $(0.0000)$ & (0.0002) & $(0.0000)$ & $(0.0000)$ & $(0.0000)$ & $(0.0014)$ & $(0.0000)$ & $(0.0000)$ \\
\hline \multirow[t]{2}{*}{$\lambda_{0}$} & 0.0212 & 0.0000 & 0.0870 & 0.0183 & 0.0157 & 0.0082 & 0.0000 & 0.0130 & 0.0000 \\
\hline & $(0.0580)$ & $(0.5000)$ & (0.0653) & $(0.0558)$ & $(0.0288)$ & $(0.1040)$ & $(0.4998)$ & $(0.1645)$ & (0.4992) \\
\hline \multirow[t]{2}{*}{$\rho$} & 0.6580 & 0.9765 & 0.1126 & 0.6242 & 0.6980 & 0.4119 & 0.9307 & 0.9409 & 0.9916 \\
\hline & $(0.0041)$ & $(0.0000)$ & (0.3967) & $(0.0400)$ & $(0.0001)$ & $(0.0221)$ & $(0.0000)$ & $(0.0000)$ & $(0.0000)$ \\
\hline \multirow[t]{2}{*}{$\gamma_{1}$} & 0.4484 & 0.0977 & 0.0948 & 0.1717 & 0.4935 & 0.3115 & 0.0451 & 0.1118 & 0.0000 \\
\hline & $(0.0257)$ & $(0.0025)$ & (0.3102) & $(0.0208)$ & $(0.0106)$ & $(0.0205)$ & $(0.0231)$ & $(0.0682)$ & $(0.4999)$ \\
\hline \multirow[t]{2}{*}{$\gamma_{2}$} & 0.2601 & 0.3859 & 0.2702 & 0.5460 & 0.1529 & 0.5357 & 0.1198 & 0.1210 & 0.1009 \\
\hline & $(0.0316)$ & $(0.0328)$ & (0.0030) & $(0.0000)$ & $(0.0200)$ & $(0.0305)$ & $(0.0678)$ & $(0.0239)$ & $(0.0125)$ \\
\hline \multirow[t]{2}{*}{$\phi$} & -0.0150 & -0.0017 & 0.0013 & -0.0095 & -0.0005 & -0.0334 & -0.0014 & 0.0040 & 0.0071 \\
\hline & $(0.0002)$ & (0.1991) & (0.3209) & $(0.0458)$ & $(0.4714)$ & $(0.0000)$ & $(0.2857)$ & $(0.0336)$ & $(0.0034)$ \\
\hline \multirow[t]{2}{*}{$\delta$} & 0.0083 & 0.0261 & 0.0235 & 0.0593 & 0.0470 & 0.0102 & 0.0277 & 0.0208 & 0.0301 \\
\hline & $(0.0004)$ & $(0.0000)$ & (0.0000) & $(0.0000)$ & $(0.0000)$ & $(0.0910)$ & $(0.0000)$ & $(0.0000)$ & $(0.0000)$ \\
\hline \multirow{2}{*}{$\begin{array}{l}\lambda_{\mathrm{t}} \\
E\left[N_{t} \mid I_{t}\right]\end{array}$} & 0.0602 & 0.1904 & 0.1287 & 0.1099 & 0.052 & 0.0783 & 0.1475 & 0.2209 & 0.2009 \\
\hline & 0.0588 & 0.1895 & 0.1288 & 0.1086 & 0.0519 & 0.0781 & 0.147 & 0.222 & 0.2006 \\
\hline
\end{tabular}

Note: This table reports estimation results for the JDSI model under the NGARCH specification for the S\&P 500 index (US) and eight emerging Asian stock market indices denominated in US dollar terms. The parameters are estimated using the maximum-likelihood method. The probability density functions are provided in the Appendix. The $p$-values are reported in parentheses. $\lambda_{\mathrm{t}}$ is the average value of the conditional arrival rate or, equivalently, ex-ante probability of jumps and $E\left[N_{t} \mid I_{t}\right]$ is the ex-post probability of jumps, which is described in the Appendix. (CH-China, IN-India, ID-Indonesia, KR-Korea, MY-Malaysia, PH-Philippines, TW-Taiwan, TH-Thailand) 


\section{Table 7}

Variance Decomposition and Higher Moments under the JDSI-NG Model

\begin{tabular}{lrrrrrrrrr}
\hline & $\underline{\mathbf{U S}}$ & $\underline{\mathbf{C H}}$ & $\underline{\mathbf{I N}}$ & $\underline{\mathbf{I D}}$ & $\underline{\mathbf{K R}}$ & $\underline{\mathbf{M Y}}$ & $\underline{\mathbf{P H}}$ & $\underline{\mathbf{T W}}$ & $\underline{\mathbf{T H}}$ \\
$\mathrm{TV}$ & & & & & & & & & \\
JV/TV & 0.0001 & 0.0003 & 0.0003 & 0.0013 & 0.0009 & 0.0005 & 0.0003 & 0.0004 & 0.0006 \\
DV/TV & 0.1428 & 0.4335 & 0.2963 & 0.4447 & 0.1718 & 0.2971 & 0.3801 & 0.3204 & 0.3821 \\
Skewness & 0.8572 & 0.5665 & 0.7037 & 0.5553 & 0.8282 & 0.7029 & 0.6199 & 0.6796 & 0.6179 \\
Kurtosis & -0.3335 & -0.1432 & 0.0765 & -0.5556 & -0.0133 & -0.0802 & -0.1153 & 0.2322 & 0.4106 \\
\hline
\end{tabular}

Note: This table reports the sample averages of the total conditional variation (TV) and its decomposition (JV/TV, DV/TV), the conditional skewness, and the conditional kurtosis of the index returns implied by the JDSI-NG model. JV/TV and DV/TV are respectively the sample averages of the variance of the jump component and the diffusion variance, each divided by the total variance. (CH-China, IN-India, IDIndonesia, KR-Korea, MY-Malaysia, PH-Philippines, TW-Taiwan, TH-Thailand) 
Figure 1

Time Series Plots of the Daily Index Level

The following graphs illustrate the time series plots of the daily index level for the US and eight emerging Asian stock markets from 7/5/95 to 8/7/02.
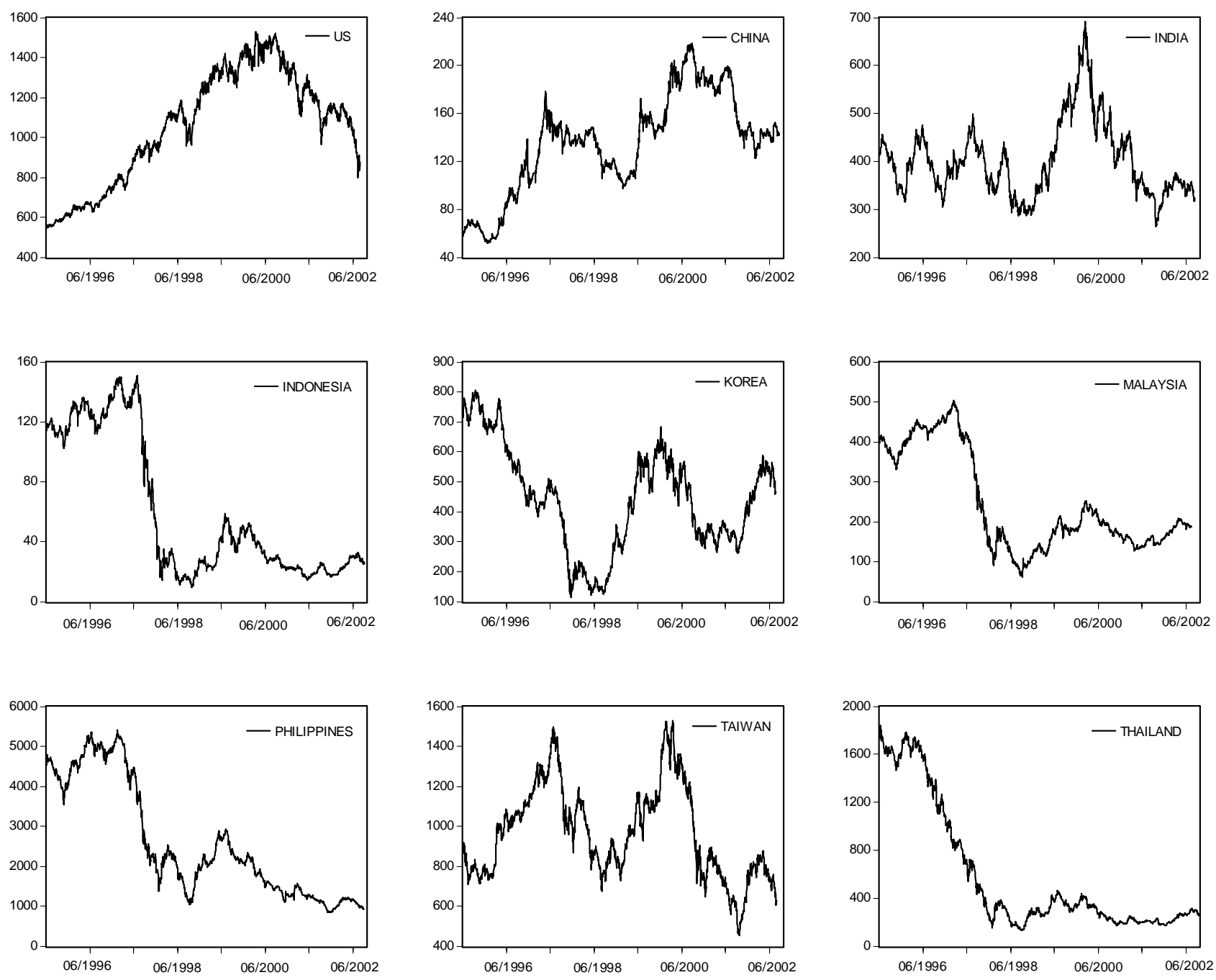
Figure 2

Time Series Plots of Daily Returns

The following graphs illustrate the time series plots of the daily returns for the US and eight emerging Asian stock markets from 7/5/95 to 8/7/02.
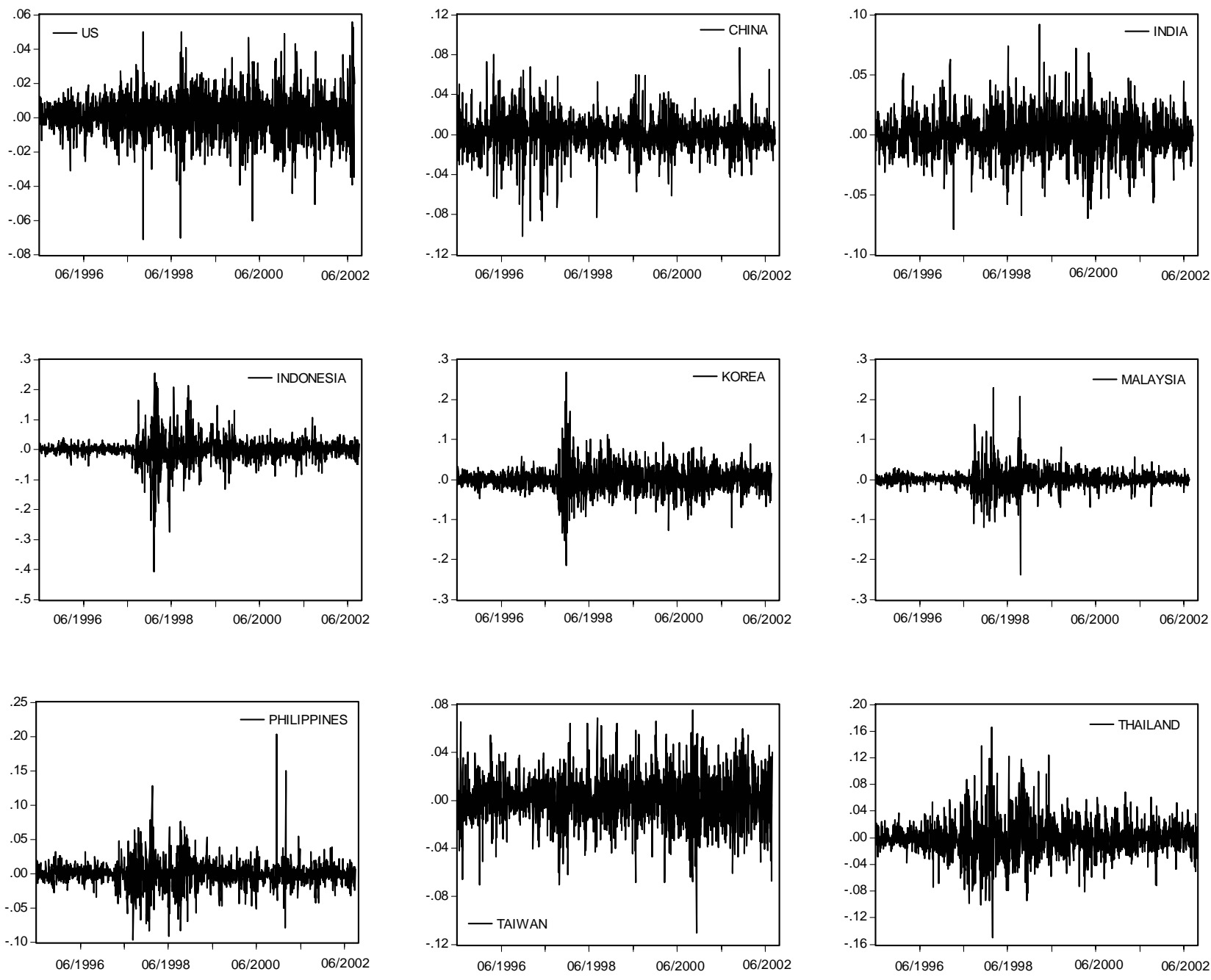
Figure 3

Time Series Plots of Conditional Volatility

The following graphs illustrate the time series plots of conditional volatilities implied by the NGARCH model for the US and eight emerging Asian stock markets from 7/5/95 to 8/7/02.
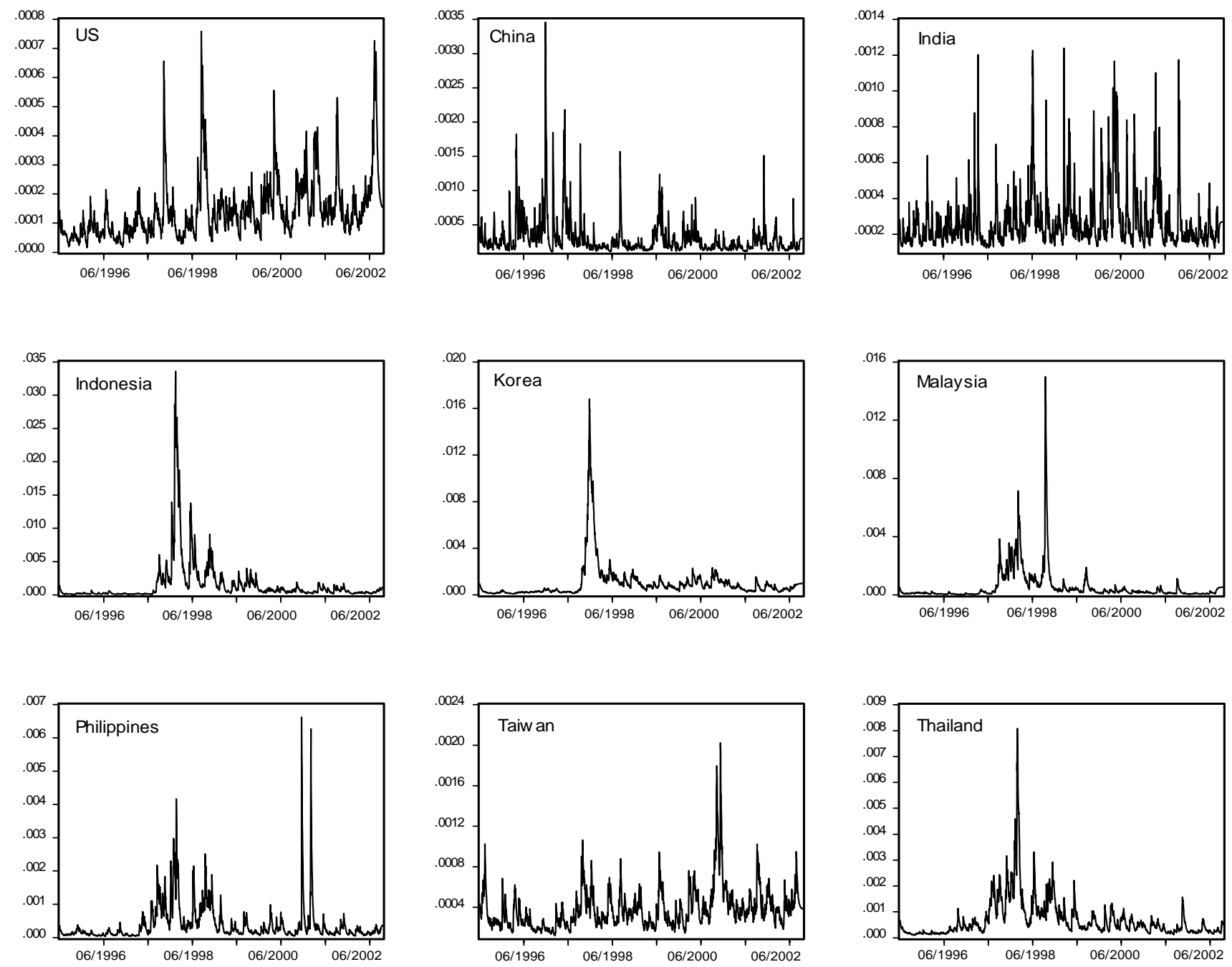


\section{Figure 4}

\section{Time Series Plots of Conditional Jump Intensity}

The following graphs illustrate the time series plots of conditional jump intensities computed from the JDAI-NG model for the US and eight emerging Asian stock markets from $7 / 5 / 95$ to $8 / 7 / 02$.
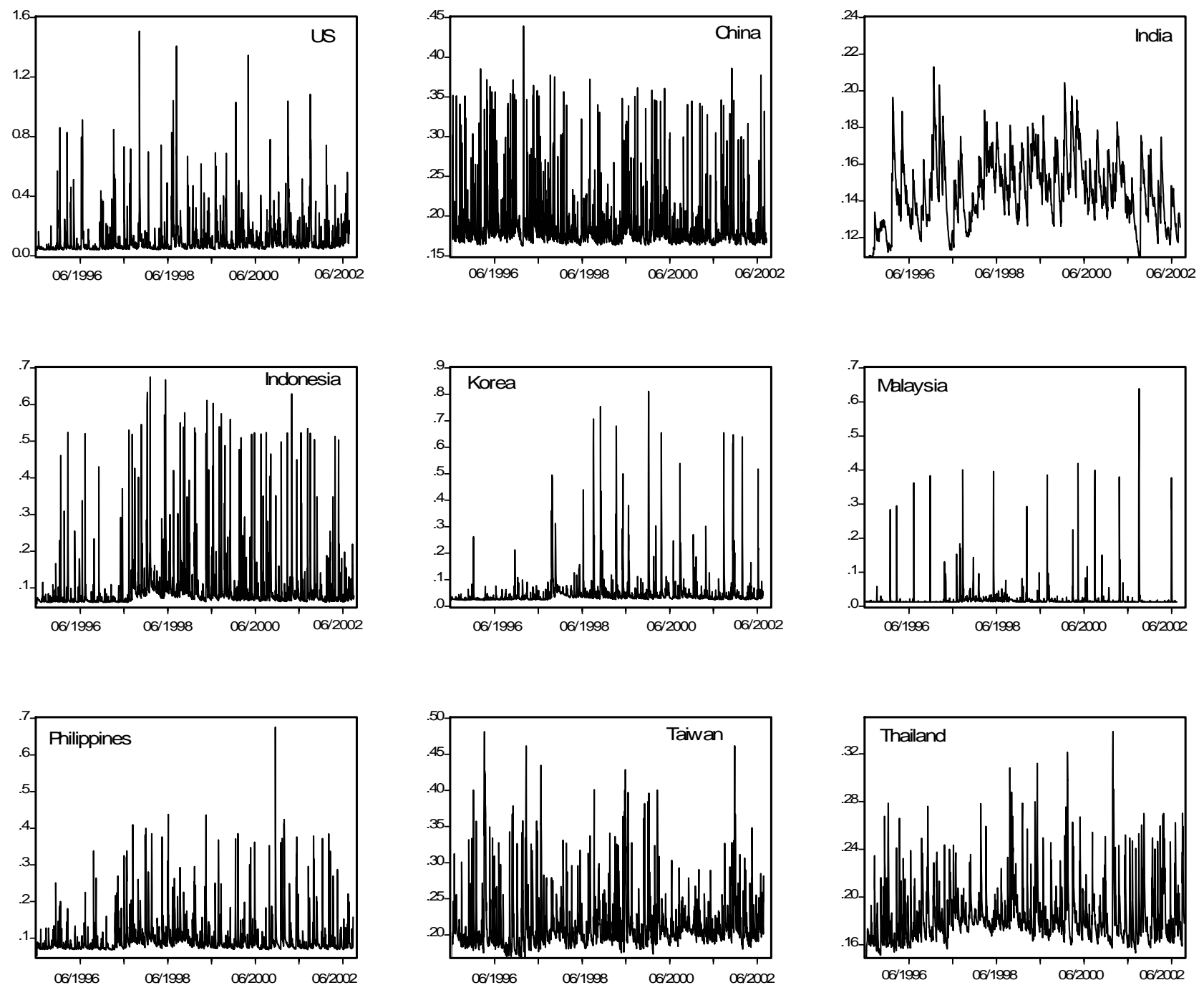